Jörg Baberowski

\title{
Die entfesselte Furie. Revolution und Diktatur in Russland
}

"In unserem tausendjährigen, gewaltigen Haus hatte sich ein großer Tod ereignet, und das Haus stand nun offen, und war erfüllt von einer unermeßlichen müßigen Menge, für die es nichts Heiliges und Verbotenes mehr gab, in keinem der Zimmer«, schrieb der Dichter Iwan Bunin am 24. April 1919 in sein Tagebuch. „Und inmitten dieser Menge schwirrten die Erben des Verstorbenen umher, ganz benommen vor Sorgen und Anordnungen, die indes niemand befolgte. Die Menge streifte von einem Zimmer ins andere, von einem Raum in den anderen, ohne auch nur eine Minute von ihren Sonnenblumenkernen abzulassen, knabbernd und kauend, und schaute vorläufig nur, schwieg einstweilen noch. Die Erben aber schwirrten umher, unaufhörlich redend, schmeichelten sich auf allerlei Art bei der Menge ein, wollten ihr und sich selbst versichern, eben sie, die machthabende Menge, hätte sich sin ihrem heiligen Zornı auf ewig die ıKettenı zerschlagen, und sie alle suchten sich selbst und der Menge einzugeben, daß sie im Grunde genommen keineswegs die Erben seien, sondern lediglich zeitweilige Verwalter, angeblich doch von der Menge selbst dazu ermächtigte. «1

Die Vorstellung von den segensreichen Wirkungen der Revolution rührt aus der Überzeugung, dass die gegenwärtige Generation nicht das Recht habe, die künftige ihren Gesetzen zu unterwerfen. So verschafft sich jeder Staatsstreich den Grund und die Legitimation, die er braucht. Alles ist im Fluss und in Bewegung, nichts ist gewiss, der Geist hat sich von den Institutionen emanzipiert. Was besteht, ist im Unrecht, was vorwärts geht, hat alles Recht auf seiner Seite. ${ }^{2}$ Die Begründungen aber kommen erst ins Spiel, wenn der Umsturz vollbracht, die

1 Bunin, Iwan: Verfluchte Tage. Ein Revolutionstagebuch, Frankfurt am Main 2008, erstmals Zürich 1935, hier S. $99 \mathrm{f}$.

2 Sloterdijk, Peter: Die schrecklichen Kinder der Neuzeit. Über das anti-genealogische Experiment der Moderne, Berlin 2014, hier S. 38 f. 
Macht gesichert ist. Natürlich wissen auch die Revolutionäre, dass vom Anfang nur sprechen kann, wer das Ende kennt, dass die Revolte eine Abfolge reiner Augenblicke ist, Augenblicke, die durch keine Vorsehung miteinander verbunden sind. Und dennoch braucht die siegreiche Revolution den Mythos, weil ihre Anführer den Bruch mit Tradition, Überlieferung und Recht legitimieren müssen. Das Volk habe die bedrückende Herrschaft des alten Regimes von seinen Schultern geworfen, nach der Freiheit verlangt, sagen sie, sobald sie an der Macht sind. Ihre eigene Revolte aber soll die letzte gewesen sein, ihr soll kein Aufruhr mehr folgen, und so setzen sie eine Geschichte in die Welt, die den Ungehorsam in einen Volksaufstand verwandelt und ihm den Anstrich des Notwendigen und Unvermeidlichen verleiht. Was im Augenblick geschah, wird als Plan und Vorsehung ausgegeben, als habe man schon immer gewusst, dass es nur so und nicht anders kommen konnte. Und so verwandelt sich die unspektakuläre Verhaftung der Minister, die sich im Oktober 1917 noch im Winterpalais aufhielten, in einen Sturm, in eine religiöse Handlung. Die Bolschewiki waren Meister effektvoller Inszenierungen, die Anerkennung nicht nur innerhalb, sondern auch außerhalb der Sowjetunion fanden. Lenin als Vollstrecker des Unvermeidlichen, die Massen, die tun, was an der Zeit ist und die Geschichte, die sich in ihnen zur Vollendung bringt. Niemals zuvor hatte es eine Revolution gegeben, die sich auf all das berief und sich auf diese Weise für alle Zeiten verewigen wollte. ${ }^{3}$

Und doch sind Macht und Herrschaft stets bedroht, und es hängt vom Augenblick und seinen Möglichkeiten ab, ob der Ungehorsam erreicht, was er will. Menschen mögen unzufrieden sein. Aber ihre Unzufriedenheit ist noch kein hinreichender Grund dafür, dass sich eine Revolte in eine Erhebung und eine Erhebung in einen Staatsstreich verwandelt. Gleiche Stimmungen können in unterschiedlichen Situationen verschiedenes bewirken. Wäre es anders, - die Revolutionen dürften gar kein Ende nehmen, geht es doch denkbar ungerecht im Leben der meisten Menschen zu. Die innere Zersetzung der Staatsmacht sei eine Voraussetzung dafür, dass Revolutionen gelängen, schrieb Hannah Arendt, aber sie seien keine notwendige Konsequenz staatlichen Zerfalls. Schon immer hätten sich auch schwache Staaten über lange Zeit am Leben erhalten. „Denn Machtzerfall wird häufig nur manifest in direkter Konfrontation; und selbst dann, wenn die Macht schon auf der Straße liegt, bedarf es immer noch einer Gruppe von Menschen, die

3 Corney, Frederick C.: Telling October. Memory and the Making of the Bolshevik Revolution, Ithaca/ N.Y. 2004, hier S. 2-8; Furet, Francois: Das Ende der Illusion. Der Kommunismus im 20. Jahrhundert, München 1996, hier S. 88. 
auf diese Eventualität vorbereitet und daher bereit ist, die Macht zu ergreifen und die Verantwortung zu übernehmen. ${ }^{4}$

Im Rückblick erscheint uns die Revolution als ein Jahrhundertgeschehen, dessen vibrierende Schwingungen bis auf den heutigen Tag zu spüren sind. Aber die Zeitgenossen wussten natürlich nicht, wohin die Brotproteste führen würden, die im Februar 1917 die Hauptstadt des Zarenreiches erschütterten. Wie viele Revolten hatte es schon gegeben, und wie oft waren sie mit leichter Hand wieder beendet worden. Im Vergleich zur ersten war die zweite Revolution nur ein Hauch im Wind. Damals, im Jahr 1905, hatte das Regime in den Abgrund geschaut. Bauernaufstände, Arbeiterproteste, Studentenunruhen, Attentate, interethnische Kriege und Judenpogrome hatten die Zentralmacht vollständig paralysiert, die liberale Opposition hatte sich gegen das Regime als politische Alternative in Stellung gebracht. Und dennoch konnte die Regierung alle Vorteile nutzen, die sich aus der Entschlossenheit und Geschlossenheit der Mächtigen ergaben. Der Zar befand sich in der Hauptstadt, die Regierung hatte die Kontrolle über Polizisten, Soldaten und ihre Waffen, und so gelang es ihr, die Aufständischen zu isolieren und sie gegeneinander auszuspielen. ${ }^{5}$

Im Februar 1917 war alles anders. Die Opposition war an nichts anderem interessiert, als die Effizienz der Exekutive zu verbessern, nicht aber daran, eine Revolution auszulösen. "Kein einziger verantwortlicher Politiker«, schrieb der liberale Dumaabgeordnete Alexander Bublikow, habe sich damals eine Revolution wünschen können, ganz gleich, was später über Absichten und Motive von den Siegern in die Welt gesetzt worden sei. Jeder habe verstanden, dass im Angesicht des Krieges von der Reorganisation der politischen Ordnung nicht die Rede sein konnte. Die revolutionären Parteien seien tot gewesen, die Liberalen hätten eine Revolution nicht einmal im Traum für möglich gehalten. ${ }^{6}$ Nirgendwo gab es überhaupt Anzeichen für eine bevorstehende Revolte. Unruhen hatte es immer schon gegeben, und immer schon waren sie auch wieder beendet worden.

Wie konnte es dann aber geschehen, dass sich die Brotrevolte in einen Aufstand, der Aufstand in eine Revolution verwandelte, die das alte Regime in nur wenigen Tagen hinwegfegte, obwohl die meisten Untertanen überhaupt nicht nach seinem Sturz verlangt hatten? Die Antwortet lautet: weil sich die Revolte auf die Hauptstadt beschränkte, weil der Zar zu Beginn der Proteste die Stadt ver-

4 Arendt, Hannah: Macht und Gewalt, 18. Aufl., München 2008, hier S. 50.

5 Vgl. dazu das Standardwerk über die erste russische Revolution von Ascher, Abraham: The Revolution of 1905, Bd.1: Russia in Disarray, Stanford/ Cal. 1988; Ders.: The Revolution of 1905, Bd. 2: Authority Restored, Stanford/ Cal. 1992.

6 Bublikov, Aleksandr: Russkaja revoljucija. Vpečatlenija i mysli očevidca i učastnika, Moskau 2016 (erstmals New York 1918), hier S. $48 \mathrm{f}$. 
ließ und nach Mogiljow, ins Hauptquartier der Armee fuhr, weil der Militärkommandant, Sergej Chabalow, die Minister des Inneren und des Krieges, Alexander Protopopow und Michail Beljajew, den Kopf verloren und sich im Zentrum von den Schaltstellen der Macht vertreiben ließen, und weil sich in Petrograd keine zuverlässigen militärischen Einheiten befanden, die dem Aufstand ein Ende hätten bereiten können.7 Und doch hätte alles anders kommen können, wenn die Bewegung der Straße ins Leere gelaufen und zerstreut worden wäre. Denn das Ende des alten Regimes kam nicht, weil Menschen auf der Straße nach Brot riefen oder Straßenbahnwaggons umwarfen, sondern es wurde erst besiegelt, als die liberale Opposition erkannte, dass die Minister unentschlossen und unfähig waren, das Nötige zu tun und die Rebellion niederzuschlagen.

Hätten die Minister und Generäle des Zaren beherzt gehandelt und die Kommunikations- und Machtmittel genutzt, die ihnen zur Verfügung standen, hätten sie sich wahrscheinlich gegen die Aufständischen durchgesetzt. In Russland waren die lokalen Machtzentren zwar mit den Ministerien in der Hauptstadt verbunden, nicht aber untereinander. Alle Informationen wurden von der Zentrale ausgegeben, und alle Informationen liefen auf sie zu. Es gab also nur eine vertikale, aber keine horizontale Kommunikation. Deshalb hatten die Aufständischen leichtes Spiel, sich durchzusetzen, nachdem sie die Macht- und Kommunikationsinstrumente der Autokratie erst einmal in ihre Hände gebracht hatten. Wäre die Revolte in der Provinz oder an der imperialen Peripherie ausgebrochen, hätte die Regierung nichts weiter tun müssen, als loyale Kosakenregimenter damit zu beauftragen, die Revolte im Keim zu ersticken. In Petrograd aber stand sie einem Heer unzuverlässiger und renitenter Reservesoldaten gegenüber, die seit Monaten untätig in den Kasernen der Stadt festsaßen und darauf warteten, an die Front geschickt zu werden. Für die Zwecke der Macht war das Heer der Untätigen nicht nur nicht zu gebrauchen, es wurde vielmehr zur leichten Beute von Agitatoren und Aufwieglern, die im Umkreis der Kasernen auf ihre Gelegenheit warteten. ${ }^{8}$

Diese Erkenntnis dämmerte den Ministern aber erst am dritten Tag der Revolte, als die Soldaten sich mit den Demonstranten verbrüderten. Die Minister hatten sich sicher gefühlt, weil die Regierungsgebäude und Paläste wie in einem Halbkreis von Kasernen umschlossen waren. Nun aber verwandelten sich die Bollwerke der Staatsgewalt in Festungen der Revolution, die Repräsentanten des autokra-

7 Eine scharfsinnige Analyse des Geschehens findet sich in den Erinnerungen des Admirals Aleksandr Bubnov: Bubnov, Aleksandr: V carskoj stavke, New York 1955, hier S. 293 - 321.

8 Bubnov, V carskoj stavke, S. 306; Paléologue, Maurice: Am Zarenhof während des Weltkrieges. Tagebücher und Betrachtungen, Bd. 2, München 1925, hier S. 249. Zur Armee in der Revolution vgl. das Standardwerk von Wildman, Alan: The End of the Russian Imperial Army, Bd. 1: The old Army and the soldiers' revolt (March-April 1917), Princeton/ N.J. 1980. 
tischen Staates wurden von Aufständischen eingekreist. Sie saßen in der Falle. ${ }^{9}$ Das Regime tat nichts, um seinen Untergang noch abzuwenden. Der Sozialrevolutionär Sergei Mstislawski, der damals im Haus des "Bundes republikanischer Offiziere» mit anderen Revolutionären den Soldatenaufstand koordinierte, konnte nicht verstehen, warum Chabalow Truppen im Zentrum der Hauptstadt konzentrierte, wo sie von Aufständischen eingekreist und demoralisiert werden konnten. Ohne Munition und Verpflegung, abgeschnitten von aller Kommunikation seien die Soldaten leicht zu überreden gewesen, sich auf die Seite der Revolution zu schlagen. Die Offiziere hätten es nicht gewagt, ihnen den Schießbefehl zu erteilen. Aus welchem Grund hätten sie der Fahne noch folgen sollen?

Chabalow hätte seine Truppen stattdessen aus der Stadt hinausführen, sich dort mit dem Hauptquartier verbinden und seine Einheiten keilförmig vom Rand ins Zentrum hineinführen müssen, um am Ende doch noch zu siegen, schrieb Mstislawski. Zwei loyale, mit überlegenen Waffen ausgestattete Regimenter hätten zweifellos ausgereicht, um den Aufruhr in wenigen Stunden zu beenden. Die Revolte wäre im Keim erstickt worden, die Liberalen hätten nachgegeben, die Bauernsoldaten sich der Macht der Gewehrläufe unterworfen. Chabalow aber war als Truppengeneral eine Fehlbesetzung. Und so öffneten Inkompetenz und Entscheidungsschwäche der Revolution das Feld, auf dem sie ihre Regimenter aufmarschieren lassen konnte. ${ }^{10}$

Nikolai II. und seine Minister waren keine Männer der Tat, sie simulierten die Macht nur, die sie zu repräsentieren vorgaben, und ihre Widersacher ahnten, dass es so war. Am dritten Tag der Revolte, als sie den Augenblick der Entscheidung kommen sahen, griffen sie nach der Macht. Michail Rodsjanko, der Parlamentspräsident, versorgte den Chef des Generalstabes, Michail Alexejew, und die Frontgeneräle mit dramatischen Nachrichten über das Geschehen in der Hauptstadt, beschwor sie, den Zaren zur Ernennung einer Regierung zu drängen, die das Vertrauen der Gesellschaft habe, weil sonst nicht nur die Autokratie, sondern die Ordnung, und mit ihr der Krieg verloren sei. Man dürfe dem Arbeiter- und Soldatenrat und den sozialistischen Parteien nicht das Feld überlassen, müsse handeln, bevor es zu spät sei. ${ }^{11}$

9 Šklovskij, Viktor: Kindheit und Jugend, Frankfurt am Main 1968, hier S. 153.

10 Mstislavskij, Sergej: Pjat' dnej. Načalo i konec Fevral'skoj revoljucii (Biblioteka russkoj revoljucii), Moskau 2017 (erstmals Berlin 1922), hier S. 24-26; Vgl. auch die Erinnerungen des Offiziers Lew TuganBaranowski in: Lyandres, Semion: The Fall of Tsarism. Untold Stories of the February 1917 Revolution, Oxford 2013, S. 120.

11 Telegramma predsedatelia Gosud. Dumy Rodsianko gen. Alekseevu, 26 fevralia 1917 g., in: Krasnyj Archiv 21 (1927), hier S. 5-6; Blok, Aleksandr: Poslednie dni starogo režima, in: Archiv Russkoj Revoljucii 4 (1922), S. 5-54; Hasegawa, Tsuyoshi: The February Revolution: Petrograd 1917, Seattle/WT 1981. 
Nikolai II. traf stattdessen eine fatale Entscheidung, als er erfuhr, dass seine Kinder an den Masern erkrankt waren. Am 28. Februar verließ er das Hauptquartier in Mogiljow, um mit dem kaiserlichen Zug nach Zarskoe Selo zu fahren und sich mit seiner Familie zu vereinen. Davon hatte ihm Alexejew abgeraten. Er werde sich entweder ins kommunikative Abseits bringen oder in Zarskoe Selo zu einem Gefangenen der Revolution werden. Hätte der Zar seine Familie nach Mogiljow, ins Hauptquartier, eskortieren lassen, hätte er das Heft des Handelns in der Hand behalten. So aber fuhr er ins Nirgendwo. ${ }^{12}$

Tatsächlich kam er nicht weit, weil die Revolutionsregierung den Eisenbahnverkehr überwachte und Bublikow, der Verkehrsminister des Provisorischen Dumakomitees, Nikolai und seine Generäle mit Falschmeldungen versorgte. Die Bahnstrecke nördlich von Bologoje, zwischen Twer und Petrograd, sei von meuternden Soldaten blockiert, teilte er ihnen mit, und im Glauben, dass die Revolution gesiegt und die Meuterer die Lage unter Kontrolle hätten, gaben sich Zar und Generalität geschlagen. General Nikolai Iwanow, den der Zar zum Diktator ernannt und mit drei Kompanien nach Petrograd geschickt hatte, kehrte unverrichteter Dinge wieder zurück, weil er den Versicherungen Bublikows Glauben schenkte, dass die Schienenwege nach Norden blockiert worden seien. ${ }^{13}$ Nikolai selbst gab seinen Plan auf, nach Zarskoe Selo zu reisen, drehte um und fuhr nach Pskow, ins Hauptquartier der Nordwestfront, wo ihn General Ruzski, der sich inzwischen schon mit der Provisorischen Regierung arrangiert hatte, bekniete, auf den Thron zu verzichten, weil es keinen anderen Ausweg aus der Krise mehr geben könne. Alle Generäle, auch der Onkel des Zaren und Statthalter im Kaukasus, Großfürst Nikolai Nikolajewitsch, hätten sich in diesem Sinn erklärt. Nikolai II. fügte sich sogleich, er verzichtete auf den Thron, dankte erst zugunsten seines Sohnes Alexei ab, bestimmte dann aber seinen Bruder, Michail Alexandrowitsch, zu seinem Nachfolger, weil er den minderjährigen Thronfolger nicht allein lassen wollte. Am 1. März kamen die Abgesandten der Duma, Wasili Schulgin und Alexander Gutschkow, nach Pskow, um im Salonwagen des kaiserlichen Zuges die Abdankungsurkunde entgegenzunehmen. ${ }^{14}$

Alle Versuche, Herrschaft festzusetzen, beruhten auf der Voraussetzung ihrer Mitteilbarkeit und Durchsetzungsmächtigkeit. Was man will, das muss man auch tun können. Im Jahr 1905 hatte die Staatsgewalt über den Aufstand triumphiert,

12 Bubnov, V carskoj stavke, S. 309-311; Vojekov, Vladimir: S Carem i bez carja. Vospominanija poslednogo dvorcovogo komendanta imperatora Nikolaja II., Moskau 1995, hier S. $224 \mathrm{f}$.

13 Lomonosov, Jurij: Vospominanija o martovskoj revoljucii 1917 g., Stockholm 1921, hier S. 45.

14 Šul'gin, Vasilij: Dni. 1920 god, Moskau 2017, hier S. 173 - 184; Steinberg, Mark D./ Khrustalev, Vladimir M. (Hrsg.): The Fall of the Romanovs. Political Dreams and Personal Struggles in a Time of Revolution (Annals of communism), New Haven/ CT 1995, hier S. 87-115. 
weil sie die Infrastruktur für ihre Zwecke noch nutzen konnte. Sie kontrollierte Telegraphenämter, Bahnhöfe und Schienenwege, auf denen Informationen übermittelt und auch die Soldaten transportiert werden konnten, die den Unruhen ein Ende setzten. Die Strafexpeditionen, die Innenminister Pjotr Durnowo nach Sibirien, in die Wolgagebiete, in die baltischen und kaukasischen Gouvernements entsandte, kamen mit der Eisenbahn, und sie hinterließen entlang der Bahnlinien eine Spur der Verwüstung. Erst brannten die Herrenhäuser, dann die Bauernkaten. ${ }^{15}$

Der Militärkommandant von Petrograd, Chabalow, Kriegsminister Beljajew und Innenminister Protopopow aber waren überfordert. Protopopow erklärte zu Beginn der Unruhen, dass Polizei und Gendarmerie keine Hilfe benötigten, um die Ordnung in der Hauptstadt wieder herzustellen, und Chabalow glaubte, sich nicht nur auf die Offiziersschüler, sondern auch auf die Reservisten verlassen zu können, die sie in den Kasernen untergebracht hatten. ${ }^{16}$ Aber sie taten nichts, um die stählernen und steinernen Bastionen der Herrschaft zu sichern, Bahnhöfe und Telegraphenämter gegen Übergriffe zu schützen. Und so brachten die Aufständischen Schienen- und Kommunikationswege, Kasernen und Bahnhöfe in wenigen Stunden in ihre Gewalt und stellten sie in den Dienst der Erhebung. Chabalow war zwar ein General ohne Fronterfahrung, aber hätte doch immerhin wissen müssen, dass sich Machtfragen ohne die Beherrschung der Infrastrukturen gar nicht beantworten lassen. Davon hatten auch die liberalen Duma-Politiker schon gehört, wenngleich sie erst nach Tagen begriffen, was getan werden musste, um die Macht zu sichern. ${ }^{17}$

Alexander Bublikow, der Ingenieur unter den Liberalen, hatte hingegen sofort erkannt, dass die Macht von ihren Kommunikationskanälen abgeschnitten werden musste, wenn die Revolution erfolgreich sein wollte. Was konnte ein Kriegsminister schon ausrichten, der seine Generäle nicht mehr erreichen und Truppen nicht mehr in Bewegung setzen konnte ${ }^{18}$ Die Revolutionäre mussten den Fluss der Informationen und Waffen unterbrechen und die Festungen isolieren, in denen sich die Macht verschanzt hielt. Die Macht musste eingekreist und bewegungsunfähig gemacht werden. Allein davon hing der Erfolg des Aufstandes in diesen Tagen ab. Solange Beljajew und Chabalow mit dem Hauptquartier des Zaren und dem Generalstab verbunden waren, konnte sich die Konterrevolution am

15 Ascher, The Revolution of 1905. Authority Restored, S. 21-41; Maksakov, Vladimir (Hrsg.): Karatel'nye ekspedicii v Sibiri v 1905 - 1906 gg. Dokumenty i materialy, Moskau 1932.

16 Bubnov, V carskoj stavke, S. 307.

17 Bublikov, Russkaja revoljucija, S. 57-62.

18 Zur Bedeutung der Infrastruktur für das Leben vgl. van Laak, Dirk: Alles im Fluß. Die Lebensadern unserer Gesellschaft, Frankfurt am Main 2018, S. $282-287$. 
Ende doch noch gegen die Insurgenten durchsetzen. Die Revolutionäre begriffen, dass nicht die Kunst der Rede und die Güte der Absichten über Erfolg oder Misserfolg des Aufstandes entscheiden würden, sondern die Kontrolle über Verkehrsund Kommunikationswege. Niemand würde sich einer Staatsmacht beugen, die weder richten noch strafen konnte. Wer keinen Gehorsam mehr findet, hat auch keine Macht.

Und so machte sich Bublikow in Begleitung eines militärischen Konvois auf den Weg, besetzte das Verkehrsministerium und das Telegraphenamt. Wenig später übermittelte er eine Nachricht an alle Bahnstationen des Landes: die alte Regierung sei machtlos und das Verkehrsnetz in den Händen der Revolution. Alle Anordnungen der Revolutionsregierung müssten befolgt werden. «Die Heimat erwartet von Euch mehr als nur die Erfüllung der Pflicht. Sie wartet auf einen Umschwung!« Schon am nächsten Tag sei die Nachricht von der Revolution und dem Ende der zarischen Regierung in ganz Russland bekannt geworden, schrieb er in seinen Erinnerungen. Die Anordnung des Verkehrskommissars war überhaupt die erste Nachricht, die von den Revolutionären in die Welt hinausgerufen wurde. Sie war ein untrügliches Zeichen dafür, dass über den Sieg nicht das Wort, sondern das Medium entschied, mit dem das Wort zum Adressaten kam. ${ }^{19}$

Das Zentrum staatlicher Macht löste sich auf, nachdem die Opposition der Regierung den Todesstoß versetzt und den Zaren vom Thron gestürzt hatte. Der Zerfall der staatlichen Autorität war also die Voraussetzung, nicht die Folge der siegreichen Revolution. Jetzt erst konnte der Geist des Aufruhrs vom Zentrum in die Provinzen gelangen, auf dem Wege der Verordnung und der systematischen Zerstörung aller Fundamente, auf denen der Staat des Zaren errichtet worden war. Wladimir Nabokow, der im Auftrag der Provisorischen Regierung die Verzichtserklärung des Großfürsten Michail Alexandrowitsch formulierte, sah klarer als andere, was die zweifache Abdankung bedeutete. Sie löste eine Staatskrise aus, die sich auf legalem Weg nicht mehr bewältigen ließ. Der Zar hätte nicht einmal abdanken dürfen, weil in den Thronfolgegesetzen zwar vom Tod, nicht aber vom Verzicht auf den Thron die Rede war. Man habe also den politischen Tod des Zaren unterstellen müssen, um die Abdankung zu legitimieren und seinen Sohn mit den Insignien der Macht auszustatten. Unter gar keinen Umständen aber hätte Nikolai zugunsten seines Bruders auf den Thron verzichten dürfen. Dieser illegitime Akt sei nur deshalb unbeachtet geblieben, weil die Parlamentarier glaubten, unverzüglich handeln zu müssen und weil sie auf die Monarchie als Legitimationsgrundlage ihrer Regierung nicht verzichten wollten. Denn die Verfassung des 
Jahres 1906 war vom Zaren gewährt, nicht vom Parlament verabschiedet worden, und auch die Regierung hatte er allein eingesetzt. Ohne die Zustimmung des Herrschers konnte es keinen legitimen Systemwechsel geben. Die Monarchie war die einzige Legitimation der politischen Ordnung und die einzige Klammer gewesen, die das Vielvölkerreich zusammengehalten hatte. Michail aber mochte und konnte kein Herrscher sein, dem es an einer Legitimation fehlte. ${ }^{20}$ Nun hatten die Usurpatoren nichts mehr, worauf sie sich berufen konnten. Sie waren Repräsentanten einer Revolution geworden, die sie eigentlich nicht gewollt hatten.

Die Minister der Provisorischen Regierung waren Machthaber wider Willen, die von niemandem beauftragt worden waren. Sie hatten einen Ausnahmezustand geschaffen, ohne zu wissen, was sie mit ihm anfangen sollten. Alle Entscheidungen seien provisorischer Natur, weil endgültige Entscheidungen nur von einer frei gewählten verfassunggebenden Versammlung getroffen werden könnten, so erklärten sie. Und auch der Arbeiter- und Soldatenrat, der in diesen Tagen entstand und sich auf den Willen des Volkes berief, machte von seinen Möglichkeiten keinen Gebrauch. Wenngleich er über die Waffen der Soldaten gebot, lehnte er es ab, die Regierungsgeschäfte an sich zu reißen. Stattdessen traten Sozialisten in die Provisorische Regierung ein und banden sich an das Zukunftsversprechen, dass über die Verteilung des Landes an die Bauern, über Krieg und Frieden, Recht und Gesetz, erst entschieden werden könne, wenn die Konstituante zusammengetreten sei. Es gab für niemanden eine andere Legitimation als den Willen zur Macht, nachdem alle anderen Quellen der Rechtfertigung, Verfassungen, Traditionen und Wahlen ausgetrocknet waren, aber es fand sich auch niemand, der die Rolle des Diktators auf Zeit hätte annehmen wollen. ${ }^{21}$

Auch Alexander Kerenski, der im Juli 1917 die Regierungsgeschäfte übernahm und auf den Rückhalt des Arbeiter- und Soldatenrats, der Provisorischen Regierung und fast aller Generäle zählen konnte, mochte nicht über seinen Schatten springen und alles auf eine Karte setzen. Zwar entwarf er sich in der Öffentlichkeit als Sozialrevolutionär und Feldherr napoleonischen Formats, hielt hysterische Reden, fiel öffentlich in Ohnmacht und warf sich in theatralische Posen. In Wirklichkeit aber war er nur ein Repräsentant simulierter Staatlichkeit, ein eitler Duce, der nichts zu vertreten und zu verteidigen hatte und der im entscheidenden Augenblick, als die Machtfrage gestellt wurde, kläglich versagte. ${ }^{22}$ Wann hat-

\footnotetext{
20 Nabokow, Wladimir: Petrograd 1917. Der kurze Sommer der Revolution, Berlin 1992 (erstmals erschienen im Archiv Russkoj Revoljucii, Bd. 1, 1922), S. $34 \mathrm{f}$.

21 Zur Provisorischen Regierung und ihren Anfängen vgl. Pipes, Richard: Die russische Revolution, Bd. 1: Der Zerfall des Zarenreiches, München 1992, hier S. 473 - 577.

22 Kolonickij, Boris: „Tovarišč Kerenskij». Antimonarchičeskaja revoljucija i formirovanie kul'ty "voždja naroda». Mart-ijun' 1917 goda (Serija Historia Rossica), Moskau 2017, hier S. 173 - 209.
} 
te es in Russland jemals eine Regierung gegeben, die Angst vor der eigenen Macht hatte?

Die Provisorische Regierung zerbrach an der Aufgabe, Diktatur zu sein, weil sie weder die alte Ordnung wiederherstellen wollte, noch eine neue errichten konnte. Stattdessen arbeitete sie an ihrer Selbstzerstörung. Ihr Regierungschef, Fürst Georgi Lwow, ein honoriger Mann von liberaler Gesinnung, war für die Aufgabe, eine neue Ordnung zu stiften, denkbar ungeeignet. "Die Seele des russischen Volkes«, erklärte er einmal, "stellte sich als eine in ihrem Wesen universale demokratische Seele heraus."Sie wolle sich mit den Demokratien in aller Welt nicht nur verschmelzen, sondern sie anführen und die Menschheit auf den »Weg des Fortschritts « führen. ${ }^{23}$ Sobald das russische Volk von der Freiheit gekostet habe, werde es von selbst lernen, sich im Geist der westlichen Demokratien zu verwalten. Wer so veranlagt war, brauchte weder Führung noch Steuerung. Am 5. März 1917 erklärte Lwow deshalb, dass im »Interesse der Verteidigung des Staates« alle Gouverneure und ihre Stellvertreter in den Provinzen ihrer Ämter enthoben seien. Der Staatsrat, dem alle hohen Würdenträger des Zarenreiches angehörten, wurde aufgelöst, angesehene und kompetente Richter, Senatoren und Staatsanwälte auf die Straße gesetzt. Wenig später wurden tausende hohe Beamte in der Zivil- und Militärverwaltung aus dem Dienst entlassen, die Polizei und die Gendarmerie aufgelöst und durch eine Volksmiliz ersetzt. Lwow enthob nicht nur die Gouverneure und Polizeioffiziere ihrer Ämter, er weigerte sich, der Verwaltung in den Provinzen Befehle zu erteilen. Anweisungen gehörten der Vergangenheit an, erklärte er Amtsträgern aus der Provinz, die gekommen waren, um zu hören, welche Direktiven die neue Regierung für sie bereithielt. In einem Interview, das Lwow am 7. März den Vertretern der Presse gab, erklärte er: „Das ist eine Frage der alten Psychologie, die Provisorische Regierung hat die alten Gouverneure abgesetzt, aber neue wird sie nicht ernennen. Man wird sie in den Provinzen auswählen. Solche Fragen sollten nicht im Zentrum, sondern von der Bevölkerung selbst entschieden werden. (24 $^{24}$

Die Fragmentierung der Macht vermehrte die Institutionen und Behörden in Windeseile. In jeder Stadt gab es nun eine Duma und einen Sowjet, in allen Randregionen des Imperiums entstanden nationale Komitees und Bauernverbände, die für sich beanspruchten, für alle zu sprechen. Nicht Kompetenz und Zuständigkeit, Recht und Gesetz entschieden nun darüber, wer wem eine Anordnung erteilen konnte, sondern die Macht, den eigenen Willen notfalls mit Gewalt gegen an-

23 Zitiert in: Figes, Orlando: Die Tragödie eines Volkes. Die Epoche der russischen Revolution 1891 bis 1924, Berlin 1998, hier S. 380.

24 Miljukov, Pavel: Istorija vtoroj russkoj revoljucii, Moskau 2001, hier S. 61. 
dere durchsetzen zu können. In früheren Zeiten hatten die Bauern nach Landhauptleuten und Gouverneuren gerufen, wenn Entscheidungen getroffen werden mussten, jetzt wandten sie sich an die Sowjets und die zahlreichen Soldatenkomitees, die überall wie Pilze aus dem Boden schossen und über die die Provisorische Regierung keine Befehlsgewalt hatte. Wer brauchte dann aber eine Regierung, die kein anderes Ziel verfolgte, als Wahlen herbeizuführen, die sie überflüssig machen würde, die auf Zukünftiges verwies, aber schon damit überfordert gewesen wäre, den Verkehr auf dem Newski-Prospekt zu regeln? Auch konnte und wollte niemand gegen die Stimmung auf der Straße regieren und den Karneval des Volkes unterbinden. „Es war der Umsturzrausch, der unbewußte Bolschewismus, der auch die nüchternsten Hirne verdreht hatte», erinnerte sich Nabokow an jene Tage. ${ }^{25}$

Als die Gefängnistore geöffnet und die Gerichtssäle geschlossen wurden, konnte auf die eigene Unversehrtheit nur noch vertrauen, wer sich selbst munitionierte. Der Gesellschaftsvertrag wurde aufgekündigt, das staatliche Gewaltmonopol zerfiel. Waffen gerieten in die Hände von Jedermann, jeder, der ein Gewehr trug oder sich zum Vorsitzenden eines revolutionären Militärkomitees erklärte, konnte sich zum Herrn über Sicherheit und Ordnung, manchmal auch über Leben und Tod erheben. Milizionäre und Soldaten dienten nicht mehr dem Staat, sondern nur noch sich und ihresgleichen, und sie verwandelten sich in Räuber und Wegelagerer, die sich von jenen, die sie bekämpfen sollten, kaum noch unterschieden. Auch die berüchtigten "Diebe im Gesetz» (vory v sakone), Berufsverbrecher, die im März 1917 aus den Gefängnissen entlassen worden waren, brachten sich mit abscheulichen Gewalttaten in Erinnerung. Schon in den ersten Tagen der Revolte wurden allein in Petrograd über 1.400 Menschen getötet, Wohnungen verwüstet, Häuser in Brand gesetzt, Polizisten gejagt und um ihr Leben gebracht. ${ }^{26}$

Auf den Straßen Petrograds ließ der Mob seinen Leidenschaften freien Lauf. Diebe wurden gelyncht, in Kanälen ertränkt oder zu Tode geprügelt, Menschen, deren Gesichter und Kleider sie als Mitglieder der Oberschicht auswiesen, wurden ausgeraubt und getötet. Der linke Sozialrevolutionär Isaak Steinberg, der Lenin bis September 1918 als Volkskommissar für Justiz diente, räumte später selbstkritisch ein, dass man hätte wissen können, was die Selbstjustiz für die öffentliche Ordnung bedeuten würde: „Für diese widerwärtige Erscheinung im Volksleben, wenn unter Pfeifen, Johlen, wildem Gelächter und geheucheltem Mitleid die Men-

\footnotetext{
25 Nabokow, Der kurze Sommer der Revolution, S. 37.

26 Sorokin, Pitirim: Leaves from a Russian Diary, New York 1924, hier S. 15f.; Hasegawa, Tsuyoshi: Crime and Punishment in the Russian Revolution, Cambridge/Mass. 2017, hier S. 167-192; Smith, Douglas: Der letzte Tanz. Der Untergang der russischen Aristokratie, Frankfurt am Main 2014, hier S. $110 \mathrm{f}$.
} 
ge, die groß an Zahl und an Massivität ist, beharrlich, ausdauernd, raffiniert und lüstern den hilflosen, vor Furcht halbtoten, für kleine Verbrechen verprügelten Dieb oder Räuber verhöhnt, bevor sie ihn im Fluss ertränkt und während er ertrinkt, noch Steine hinterherwirft oder durch dutzende Schüsse an die Wand erschießt, - für diese Erscheinung kann es keinerlei Rechtfertigung geben." All diese unkontrollierten Gewaltexzesse, so Steinberg, hätten einen schweren Schatten auf die Revolution geworfen. Hier sei zu sehen gewesen, was der Revolution eigentlich noch bevorstand: die geistige "Wiedergeburt des Menschen« vorzubereiten und ins Werk zu setzen. ${ }^{27}$

Iwan Bunin fand, dass solche Träumereien lächerlich und sinnlos seien. Die Liberalen hätten geglaubt, „Stepan Rasin« und seinesgleichen seien an der sozialen Frage interessiert gewesen, hätten sie zum Aufruhr aufgestachelt, dann aber bemerkt, dass den Rächern die Flasche näher als der Rechtsstaat gewesen sei. „In Friedenszeiten vergessen wir, daß es auf der Welt von solchen Mißgeburten nur so wimmelt, in Friedenszeiten sitzen sie im Gefängnis, in der Irrenanstalt. Doch dann kommt eine Zeit, in der das serhabene` Volk die Oberhand gewinnt. Die Türen der Gefängnisse und Irrenanstalten werden geöffnet, und das Bacchanal beginnt. ${ }^{28}$

Auch in den Provinzen breitete sich im Sommer 1917 das Virus der Anarchie aus: Deserteure, marodierende Soldaten und Matrosen, die den Augenblick der großen Enteignung nicht verpassen wollten, demütigten und terrorisierten die Herren von einst. »Bewahre uns Gott vor einem russischen Aufstand, sinnlos und erbarmungslos«. Was Alexander Puschkin 100 Jahre zuvor über die Bauernkriege des 18. Jahrhunderts in seiner Erzählung "Die Hauptmannstochter», geschrieben hatte, schien sich nun zu wiederholen. ${ }^{29}$ Die Herrenhäuser brannten wie Fackeln in der Steppe, die Knechte und Sklaven von einst plünderten in großem Stil. Die grand peur kam mit den Soldaten, die sich aus der zerfallenen Armee abgesetzt hatten und sich nun nahmen, was sie schon immer für sich beansprucht hatten. Die Gewalt verselbständigte sich. Sie löste sich von ihren Zielen und verheerte das flache Land: lettische Bauern, die Gutshöfe deutscher Barone in Brand setzten, Muslime, die sich an armenischen Kaufleuten in Baku vergriffen, armenische Soldaten der zerfallenen zarischen Armee, die muslimische Dörfer verwüsteten,

27 Štejnberg, Isaak: Nravstvennyj lik revoljucii 1917-1919 (Biblioteka russkoj revoljucii), Moskau 2017 (erstmals Berlin 1923), hier S. $43 \mathrm{f}$.

28 Bunin, Verfluchte Tage, S. 203.

29 Puškin, Aleksandr: Kapitanskaja dočka, in: Polnoe sobranie sočinenij A. S. Puškina, hrsg. von P. N. Krasnov, Sankt Peterburg 1904, S. 480 - 529, hier S. 524; Channon, John: The Peasantry in the Revolutions of 1917, in: Revolution in Russia. Reassessments of 1917, hrsg. von Edith Rogovin Fraenkel/ Jonathan Fraenkel, Cambridge 1992, S. 105 -130; Keep, John: The Russian Revolution. A Study in Mass Mobilization (Revolutions in the modern world), New York 1976, S. 207-216. 
ukrainische Bauern, die Juden töteten, Polen, die Krieg gegen Ukrainer führten. Ganz Russland stand in Flammen, weil es keine Zentralgewalt mehr gab, die dem großen Krieg ein Ende hätte bereiten können. ${ }^{30}$

Nicht als Akt der Emanzipation, sondern als blutiger Karneval des Volkes brachte sich die Revolution zu Wort. Und so trat die Ernüchterung schon nach wenigen Wochen ein, als alle Institutionen zerfielen, die Recht und Gesetz noch hätten erzwingen können. Denn was hat der Mensch von seinen Rechten, wenn er sie zwar kennt, von ihnen aber keinen Gebrauch machen kann, weil sie nicht geschützt werden? Der liberale Historiker und erste Außenminister der Revolution, Pawel Miljukow, verglich die Ereignisse des Jahres 1917 mit einer geologischen Umwälzung. Die untersten Schichten der sozialen Ordnung seien nach oben gespült, die Fundamente einer über Jahrhunderte gewachsenen Ordnung ins Wanken gebracht worden. Man dürfe die russische Revolution nicht als Einlösung marxistischer Freiheitsversprechen verstehen, sondern müsse sie als Verwirklichung der russischen Freiheit, als Ausdruck jener erbarmungslosen Gewalt begreifen, die es immer schon gegeben habe, deren zerstörerische Wirkungen aber erst durch die Revolution zur Entfaltung gekommen seien. Sie vollendete, was auf den Schlachtfeldern des Ersten Weltkrieges begonnen hatte und bestellte das Feld, auf dem sich der Ordnungsentwurf der Bolschewiki mit rücksichtsloser Gewalt durchsetzen konnte. ${ }^{31}$

Als Matrosen und Arbeiter im Sommer 1917 Petrograd in einen Belagerungszustand versetzten, versandete der Protest schon nach wenigen Stunden, weil die Demonstranten, die die Straßen okkupiert hatten, nicht wussten, was sie tun sollten und weil die bolschewistischen Aufwiegler der wütenden Menge kein Ziel setzten. Ohne Ziel und Steuerung aber wurde aus der amorphen Masse keine bewegende Kraft. ${ }^{32}$ Kein Revolutionär übernahm den Oberbefehl, niemand stellte die Machtfrage und niemand wollte sie beantworten. Niemand entschied über den Ausnahmezustand. Ohne Anführer aber, die der Gewalt Ziele setzen und ihr eine Form geben, läuft der Aufruhr ins Leere. Die Minister der sozialistischen Parteien, Menschewiki und Sozialrevolutionäre, zögerten, als sich ihnen die Gelegenheit bot, die Provisorische Regierung zu verlassen und die Macht in die Hände der Räte zu legen: "Ergreife die Macht, Du Hurensohn, wenn man sie Dir gibt«, - so rief ein Soldat dem Vorsitzenden der Sozialrevolutionären Partei, Viktor Tscher-

30 Zur Revolution im Kaukasus vgl. exemplarisch Baberowski, Jörg: Der Feind ist überall. Stalinismus im Kaukasus, München 2003, hier S. 97-141.

31 Miljukov, Pavel: Istorija vtoroj russkoj revoljucii, Moskau 2001 (erstmals zwischen 1921 und 1924 in mehreren Bänden in Sofia erschienen), hier S. 17; Beyrau, Dietrich: In der Falle der Gewalt: Vom ersten Weltkrieg in den Bürgerkrieg, in: Ders.: Krieg und Revolution. Russische Erfahrungen, Paderborn 2017 , S. $200-225$.

32 Figes, Die Tragödie eines Volkes, S. 446 - 464. 
now, zu, der von Recht und Gesetz sprach, von den Möglichkeiten des Augenblicks aber nichts verstand. ${ }^{33}$ Er und seinesgleichen aber fürchteten sich vor den Konsequenzen ihrer eigenen Entscheidungen, vor der Elementargewalt der Massen, die sie entfesseln würden, wenn sie alles auf eine Karte setzten:

»Wie sie sich vor ihr fürchteten«, schrieb der Sozialrevolutionär Mstislawski, der selbst dem Exekutivkomitee des Arbeiter- und Soldatenrates angehörte. «Als ich unsere sSozialisten sah, wie sie in jenen Tagen vor den Massen auftraten, die in die Säle des Taurischen Palais' strömten, da empfand ich schmerzhaft und angeekelt, wie sie innerlich zitterten. Ich sah, welche Anstrengung es sie kostete, ihre Augen nicht vor den treuherzig offenen Seelen der mit ihnen verbundenen Arbeiter und Soldaten zu senken, vor ihrem klaren, gläubigen, erwartungsvollen Blick. ... Vorgestern war es noch leicht für sie gewesen, sich für Vertreter und Führer dieser Arbeitermassen zu halten. Ohne die geringste Spannung in der Stimme sprachen die friedlichsten dieser Parlamentssozialisten die schrecklichsten Worte sim Namen des Proletariats`. Aber als dieser theoretische Proletarier direkt vor ihnen stand, in seiner ganzen Größe, mit der ganzen Kraft seines abgemagerten Fleisches und aufrührerischen Blutes, als diese aufrührerische, wahrhaftige Kraft fühlbar wurde ... da murmelten die bleichen Lippen der `Führer anstelle der gestrigen kämpferischen Aufrufe unwillkürlich beruhigende Worte. Sie begannen sich zu fürchten. $^{34}$

Lenin hatte keine Angst, denn er wusste, dass die Grausamkeit und die anarchistischen Gefühle Triebkräfte waren, die sich die Diktatur zunutze machen konnte. Er hatte sogleich erkannt, dass sich nicht wiederholen durfte, was während des Juli-Aufstandes geschehen war. Von Vorschriften und Verordnungen würde er sich nicht leiten lassen, von den Gesetzen der Geschichte, die er sich nach Belieben zurechtlegte, schon gar nicht. Man schafft klare Verhältnisse und macht sich über die Legitimation Gedanken, wenn erreicht ist, was man sich vorgenommen hat. Als General Kornilow, der Kopf der Gegenrevolution, im September zum entscheidenden Schlag ausholen und eine Militärdiktatur errichten wollte, wandte sich die Provisorische Regierung von ihm ab. Lenin sah, dass nun seine Stunde gekommen war. Und er nutzte sie. ${ }^{35}$ Trotzki, der damals den Vorsitz im Militärrevolutionären Komitee des Arbeiter- und Soldatenrates führte, bereitete die bolschewistischen Garden auf den Umsturz vor. Nichts sollte dem Zufall überlassen werden. Als Zivilisten verkleidet, spähten sie die Gebäude der Macht aus

33 Zitiert in Suchanow, Nikolai: 1917. Tagebuch der russischen Revolution, München 1967, hier S. 425 .

34 Mstislavskij, Pjat' dnej, S. 5 f.

35 Pipes, Richard: Die russische Revolution, Bd. 2: Die Macht der Bolschewiki, Berlin 1992, hier S. $179-224$. 
und brachten in Erfahrung, auf welche Weise sie Postämter, Bahnhöfe und Ministerien, Telefonleitungen und Eisenbahnstrecken unter ihre Kontrolle bringen konnten. Der eigentliche Umsturz war unspektakulär. Es gab keine Barrikaden, Feuerbrände und Straßenkämpfe. Stattdessen vollzog sich der Putsch geräuschlos, wie eine militärische Übung. Manche erfuhren erst am folgenden Tag, dass die Regierung gestürzt worden war. ${ }^{36}$ „Die bürgerlichen Klassen hatten Barrikaden, Feuerbrände, Plünderungen, Blutströme erwartet«, schrieb Lew Trotzki über den Staatsstreich, dessen Regisseur er gewesen war. "In Wirklichkeit herrschte Stille, schrecklicher als alle Donner der Welt. Lautlos verschob sich der soziale Boden. $^{37}$

Lenin und seine Anhänger waren überrascht, dass sich ihnen kaum jemand widersetzte, niemand den Versuch unternahm, sie mit Gewalt von den Schalthebeln der Macht wieder zu vertreiben. Gewalt hätte mit Gewalt vergolten werden können. Aber nichts dergleichen geschah, keine Revolte, keine Gegenwehr, die die Usurpatoren hätten ernst nehmen müssen. Jetzt aber mussten die neuen Herren eine Antwort auf die Frage finden, was sie mit der Macht anfangen sollten, die ihnen so leicht zugefallen war. Das fragte sich auch Lenins Bildungskommissar Anatoli Lunatscharski, der im Winter 1917 in seinem Büro saß und nicht begriff, warum die Gegenrevolution sich nicht bewaffnete und Vergeltung an den Usurpatoren der Macht übte. Der Menschewik und Schriftsteller Alexander Tichonow, der zu den ersten Mitgliedern des Exekutivkomitees des Arbeiter- und Soldatenrates gehört hatte, erzählte Iwan Bunin im März 1918, die Bolschewiki könnten es immer noch nicht glauben, dass sie an der Macht seien: "Lunatscharski ist nach dem Umsturz ungefähr zwei Wochen mit weit aufgerissenen Augen herumgerannt: Also nein, stellen Sie sich mal vor, wir wollten bloß eine Demonstration veranstalten, und dann so ein unerwarteter Erfolg! «38 Auch im Smolny, der Zentrale des Oktoberputsches, liefen in diesen Tagen Männer über den Flur, denen die Angst in den Augen geschrieben stand, erinnerte sich David Sagiraschwili, ein Gefolgsmann Stalins. ${ }^{39}$

Und dennoch wollte niemand mit den neuen Herren kooperieren, niemand ihnen freiwillig gehorchen. Als Trotzki, der sich für den Messias der Revolution hielt, das Außenministerium übernahm, lachten ihn die Diplomaten aus, manche quittierten den Dienst. Sie konnten sich einen Außenminister, der Lederjacken trug und pathetische Reden hielt, einfach nicht vorstellen. ${ }^{40}$ Von einer geordneten

36 Malaparte, Curzio: Technik des Staatsstreichs, Karlsruhe 1968, hier S. 11-42.

37 Trotzki, Leo: Geschichte der russischen Revolution, Frankfurt am Main 1960, hier S. 646.

38 Bunin, Verfluchte Tage, S. 51.

39 Kotkin, Stephen: Stalin, Bd. 1: Paradoxes of Power, 1878 -1928, London 2014, hier S. 233.

40 Ebd., S. 229. 
Verwaltung im herkömmlichen Sinn konnte überhaupt nicht die Rede sein. In den Tagen nach dem Umsturz raubten Soldaten die Weinkeller des Winterpalastes aus, zerschlugen Porzellan, Möbel und Gemälde. In Strömen floss der Wein auch in den nächsten Wochen. Manche lagen in der Gosse, weil sie sich zu Tode getrunken hatten: "Es stinkt und fühlt sich an wie eine Kloake, in der wir versinken«, schrieb die Dichterin Sinaida Hippius am 4. Dezember 1917 in ihr Tagebuch. »Die Schnapspogrome halten nicht eine Minute inne. Ganz >Petrograd» (hier passt der Name!) ist besoffen. Irgendwo wird immer geschossen, manchmal aus Maschinengewehren. Gerade ist auf der Wassiljewski-Insel ein grandioser Raubzug im Gange. ${ }^{41}$ Und ganz in der Nähe saß Lunatscharski in seinem Büro und dachte darüber nach, wo er seinen neuesten Artikel über revolutionäre Kultur publizieren würde.

Die Restaurants und Kabaretts der Hauptstadt waren überfüllt, auf den Straßen fanden Trabrennen statt, und die Reichen verschleuderten ihre letzten Ersparnisse. In den Moskauer Kaufmannshäusern hatten sich Räuber und Banditen einquartiert, in der Stadt herrschte zu Beginn des Jahres 1918 eine ausgelassene Stimmung, als sei die letzte Gelegenheit gekommen, das Leben in vollen Zügen zu genießen. Anarchisten, Räuberbanden und Abenteurer terrorisierten die Hauptstadt. Eines Abends zerrten sie sogar den Chef der Petrograder Tscheka, Moisei Urizki, der vom Smolny in die Innenstadt fuhr, von seinem Schlitten, zwangen ihn, sich zu entkleiden und ließen ihn nackt an der Straße stehen. Man habe sich nur noch in Gruppen auf die Straße gewagt, erinnerte sich der britische Diplomat Bruce Lockhart, stets mit der Hand am Pistolengriff. »Regelloses Schießen dauerte die Nächte durch. Die Bolschewisten schienen unfähig, mit dieser Pest aufzuräumen. ${ }^{42}$ Niemand glaubte in jenen Tagen, dass die Bolschewiki an der Macht bleiben würden. Es schien, als müsse man die scheinbar geistig verwirrten Desperados einfach eine Zeitlang geduldig ertragen, wie eine lästige Influenza, die irgendwann vorübergehen werde. Die Bürger verbarrikadierten sich in ihren Wohnungen, während auf den Straßen die Plünderungen und Sauforgien kein Ende nehmen wollten, und sie warteten darauf, dass irgendjemand dem Spuk ein Ende setzte. Lenin und Dada. So hat der amerikanische Historiker Stephen Kotkin das Geschehen in den ersten Wochen nach der Machtergreifung beschrieben. ${ }^{43}$ Chaos und Anarchie überall, und die Hoffnung der alten Elite, dass das bolsche-

41 Hippius, Sinaida: Petersburger Tagebücher 1914-1919 (Die Andere Bibliothek, Bd. 14), Berlin 2014, hier S. 255.

42 Lockart, Bruce: Vom Wirbel erfaßt. Bekenntnisse eines britischen Diplomaten, Stuttgart 1933, hier S. 221, 226.

43 Bunin, Verfluchte Tage, S. 51; Kotkin, Stalin, Bd. 1, S. 227. 
wistische Bacchanal nur eine bedeutungslose Episode in der Geschichte der sinnlosen Revolten bleiben würde.

Lenin aber wusste, wie von der Macht Gebrauch zu machen war, und er schreckte nicht davor zurück, alle Mittel einzusetzen, um sie auch zu sichern. Im April 1917 hatte er noch gefordert, nicht nur die Provisorische Regierung zu stürzen, sondern die Macht in die Hände der Arbeiter- und Soldatenräte zu legen. Davon wollte er jetzt, nachdem er selbst erfolgreich nach der Macht gegriffen hatte, nichts mehr wissen. Seine Partei hatte keine Mehrheit in den Räten, und sie würde sie auch nicht bekommen. Von der Konstituierenden Versammlung hatten die Bolschewiki schon gar keinen Gewinn. Unmittelbar nach dem Staatsstreich hatten Russlands Bürger in mehr oder weniger freien Wahlen über die Zusammensetzung des verfassunggebenden Parlaments abgestimmt. Das Ergebnis war eindeutig. Nicht die Bolschewiki, sondern die Sozialrevolutionäre eroberten die Mehrheit der Sitze im Abgeordnetenhaus, in den Metropolen Petrograd und Moskau konnten auch die Liberalen gute Ergebnisse erzielen. Wo die Bolschewiki besonders erfolgreich waren, dort triumphierten auch die Konstitutionellen Demokraten. Lenin sollte diese Lehre nicht vergessen. Die Bolschewiki hatten gesiegt, aber der Liberalismus war noch nicht tot. ${ }^{44}$ Im Januar 1918 sollte das Parlament eröffnet werden, um über die zukünftige Ordnung Russlands zu beraten und zu befinden. Lenin aber sah sich weder als Repräsentant der Räte noch als Regent, der im Amt bleiben würde, bis das Parlament über die zukünftige Ordnung entschieden hatte. Die Bolschewiki konnten nur an der Macht bleiben, wenn sie jeden Versuch unterbanden, ihrer Herrschaft rechtliche Fesseln anzulegen. Lenin löste die Konstituierende Versammlung im Januar 1918 deshalb mit der Begründung auf, über die politische Ordnung sei bereits im Oktober 1917 entschieden worden. Tausende zogen über den Newski Prospekt zum Taurischen Palais, in dem sich die Abgeordneten versammelt hatten, um ihre Loyalität zur Konstituierenden Versammlung zu bekunden. Lenins rote Garden schossen in die Menge, die Demonstration war beendet. "Die Konstituierende Versammlung», so Trotzki, "stand der revolutionären Bewegung im Weg und wurde hinweggefegt. «45

So verfuhr Lenin auch mit den Räten, auf die sich seine Herrschaft zwar berief, die sich aber bald in Organe der Exekutive verwandelten. Die bolschewistische Partei war das eigentliche Instrument der souveränen, extralegalen Entscheidung. Sie verstand und entwarf sich als Werkzeug der Revolution, und als solches

44 Radkey, Oliver H.: Russia goes to the polls. The Elections to the All-Russian Constituent Assembly, 1917 (Studies in Soviet history and society), Ithaca/ N.Y. 1990, hier S. 14-23, 34f.

45 Trotzki, Leo: Terrorismus und Kommunismus. Anti-Kautsky, Hamburg 1920, hier S. 29; Kotkin, Stalin, Bd. 1, S. 246 f. 
emanzipierte sie sich von allen rechtlichen und moralischen Begründungen. Was immer die Bolschewiki auch täten, sie vollstreckten nur, was historisch an der Zeit gewesen sei und deshalb getan werden konnte, so lautete die Selbstlegitimation der Revolutionäre, wie sie vor allem von Trotzki vorgetragen wurde. ${ }^{46}$

Revolutionen unterbrechen die Kontinuität des Geschehens und setzen Zwecke, die sich an nichts anderem orientieren als an dem Willen, zu tun, was man kann. In diesem Sinne war Lenins Diktatur souverän, weil sie über den Ausnahmezustand entschied, weil sie Neues nicht nur aus Hergebrachtem in die Welt setzte. Frei ist, wer die Wahl hat, wer sich über Bedingungen, Konventionen, Gesetze und Rechte jederzeit hinwegsetzen kann, unfrei, wer Bedingungen akzeptiert, unter denen er eine Wahl treffen darf. Mit diesen Worten könnte man die Weltanschauung zusammenfassen, die Lenin in jenen Tagen bewegte. ${ }^{47}$ Diktatur und Demokratie seien gar keine Gegensätze, sondern verschiedene Zustände der Volksherrschaft, erklärte er. Die Diktatur müsse überhaupt als eigentlicher Ausdruck der Demokratie verstanden werden, denn durch sie setze sich die Souveränität der Volksherrschaft erst in die Wirklichkeit. Die bürgerliche Demokratie sei Betrug. Man erlaubt den Arbeitern, von Zeit zu Zeit Repräsentanten zu wählen und ihnen eine Lizenz zur Bevormundung zu erteilen, ändert aber nichts an den Herrschaftsverhältnissen. Was könne und wolle ein Parlamentarier gegen Verhältnisse schon ausrichten, die ihn selbst privilegierten? Die proletarische Diktatur hingegen habe die sozialen Bedingungen auf eine Weise verändert, glaubte Lenin, »daß die werktätigen Klassen in einem in der Welt noch nie gesehenen Maße die Demokratie tatsächlich ausnutzen. «48

Lenin gestand im dritten Jahr der Revolution in entwaffnender Freimütigkeit ein, worin für ihn das Wesen der Diktatur bestand. Sie könne als Ausdruck des Volkswillens nur triumphieren, wenn sie sich von allen rechtlichen Bindungen löse und als Legitimation nur gelten lasse, dass sie könne, was sie wolle. »Die Diktatur ist eine sich unmittelbar auf Gewalt stützende Macht, die an keine Gesetze gebunden ist. Die revolutionäre Diktatur des Proletariats ist eine Macht, die erobert wurde und aufrechterhalten wird durch die Gewalt des Proletariats gegenüber der Bourgeoisie, eine Macht, die an keine Gesetze gebunden ist.» Und er zitierte Friedrich Engels mit den Worten: "Eine Revolution ist gewiß die

46 Traverso, Enzo: Im Bann der Gewalt. Der europäische Bürgerkrieg 1914-1945, München 2008, hier S. 113 -115; Agamben, Giorgio: Homo sacer, Bd. 2,1: Ausnahmezustand, Frankfurt am Main 2004, hier S. 44.

47 Žižek, Slavoj: Lenin heute. Erinnern, Wiederholen und Durcharbeiten, Darmstadt 2018, hier S. $74-$ 76; Lih, Lars T.: Lenin Rediscovered. »What is to be done?« In context, Chicago 2008, hier S. 770.

48 Lenin, Wladimir I.: I. Kongreß der Kommunistischen Internationale 2. - 6. März 1919. Thesen und Referat über bürgerliche Demokratie und Diktatur des Proletariats, in: Ders., Ausgewählte Werke, Bd. 3, Berlin (Ost) 1970, 8. Aufl., S. 171. 
autoritärste Sache, die es gibt, ein Akt, durch den ein Teil der Bevölkerung seinen Willen dem anderen Teil durch Flinten, Bajonette und Kanonen, alles das sehr autoritäre Mittel, aufzwingt; und die Partei, die gesiegt hat, muß ihre Herrschaft durch den Schrecken, den ihre Waffen den Reaktionären einflößen, behaupten. ${ }^{49}$ Auch Nikolai Bucharin, Theoretiker und "Liebling der Partei«, wie Lenin ihn nannte, gefiel sich zu jener Zeit noch in der Rolle des unerschrockenen Jakobiners, der das Notwendige erledigte und auch vor Gräueltaten nicht zurückschreckte, um zu retten, was die Bolschewiki im Oktober 1917 erkämpft hatten. In seiner Broschüre "Programm der Kommunisten«, die 1919 erschien, erklärte er: "Aber die Revolution besteht eben darin, daß sie ein Bürgerkrieg ist, und Klassen, die sich mit Kanonen und Maschinengewehren bekämpfen, verzichten auf das homerische Rededuell. Die Revolution diskutiert nicht mit ihren Feinden, sie zerschmettert sie, die Konterrevolution tut dasselbe, und beide werden den Vorwurf zu tragen wissen, daß sie die Geschäftsordnung des deutschen Reichstages nicht beachtet haben. «50 Zwanzig Jahre später starb Bucharin selbst durch eine souveräne Entscheidung, als Stalin ihn zum Verräter und Volksfeind erklären und erschießen ließ. Karl Kautsky sah schon im Jahr 1919 klarer als andere voraus, wohin die souveräne Diktatur führen würde: Mit der Diktatur sei es wie mit dem Krieg. Man könne sie leicht ins Werk setzen, aber man könne sie nicht nach Belieben wieder beenden, sobald man einmal damit begonnen habe, in großem Stil Gewalt gegen seine Widersacher einzusetzen. ${ }^{51}$

Die Bolschewiki hatten die Brücken hinter sich abgebrochen. Sie konnten nicht zurück. Lenin und seine Gefolgsleute waren keine Träumer, die sich irgendwelchen Illusionen hingegeben hätten. Sie wussten um ihre begrenzten Möglichkeiten, und um die Reichweite ihres Einflusses auf das revolutionäre Geschehen. Sie hatten keine Kontrolle über die Provinzen und über den Machtapparat des Staates, dessen Beamte ihre Regierung für illegitim hielten. Nicht einmal vertrauenswürdige Kommissare hätten sie in die Provinzen entsenden können, weil es zwar rebellische Bauern und unzufriedene Arbeiter, aber keine Kommunisten gab, die verstanden hätten, worauf das bolschewistische Staatsbildungsprojekt hinauslief. Sie wurden erst auf den Schlachtfeldern des Bürgerkrieges geboren, in der Feuertaufe exzessiver Gewalt und Gegengewalt.

\footnotetext{
49 Wladimir I. Lenin, Die proletarische Revolution und der Renegat Kautsky, in: Ders., Ausgewählte Werke, Bd. 3, 8. Aufl., Berlin 1970, hier S. 80, 83.

50 Bucharin, Nikolaj: Programm der Kommunisten, Berlin 1919, hier S. XXIII.

51 Kautsky, Karl: Terrorismus und Kommunismus. Ein Beitrag zur Naturgeschichte der Revolution, Berlin 1919, hier S. 144. Vgl. auch Halévy, Elie: L'ere des tyrannies. Ètude sur le socialisme et la guerre, Paris 1938.
} 
Wer in den Abgrund schauen muss, weil der Weg zurück versperrt ist, hat nur noch wenige Möglichkeiten, die eigene Haut zu retten. Eine Kapitulation kam für Lenin nicht in Frage. Sie wäre zweifellos das Ende für ihn und seinesgleichen gewesen, nach allem, was die Bolschewiki ihren Feinden angetan hatten. Schon vor seiner Abreise aus Zürich im April 1917 hatte Lenin zu Karl Radek gesagt. »In sechs Monaten baumeln wir am Galgen oder wir sind an der Macht «.52 Die Niederlage der Bolschewiki werde auch ihr physisches Ende, der Umsturz also eine Frage von Leben und Tod sein. Denn nun konnte sich auch die Gegenrevolution aller rechtlichen und moralischen Bindungen entledigen, nachdem die Bolschewiki die Machtfrage in ihrer ganzen Unerbittlichkeit gestellt hatten. Der Ausnahmezustand eröffnete Lenin aber auch Möglichkeiten, die der Frieden nicht bereithielt. Er konnte, als er den Bürgerkrieg heraufbeschwor, den Einsatz von Gewalt vor sich und den Gefährten als Gefahrenabwehr rechtfertigen. Lenin sprach nun von der Verteidigung der Ordnung, obwohl doch er selbst und nicht seine Gegner sie aus den Angeln gehoben hatten. Ein geschickter Schachzug, denn wer von Verteidigung spricht, ist zwar nicht zwangsläufig im Recht, diskreditiert aber den Gegner als illegitimen Herausforderer und hofft, dass in Vergessenheit gerät, wer den ersten Stein geworfen hat. "Wer stört, den entfernen wir», erklärte er am 12. Januar 1920 vor dem Zentralkomitee des Gewerkschaftsbundes. ${ }^{53}$

Am 20. November 1917 gaben die Bolschewiki den Offizieren der alten Armee ein Beispiel für die Rücksichtslosigkeit und Grausamkeit, zu der sie fähig waren. Als sich der Oberbefehlshaber der Streitkräfte, General Nikolai Duchonin weigerte, die Kampfhandlungen gegen die deutschen Truppen einzustellen, wurde er abgesetzt und angewiesen, sich in Mogiljow zur Verfügung zu halten. Duchonin hätte jetzt, wie Kornilow und seine Kameraden, fliehen und sich nach Süden absetzen können, wo die Bolschewiki noch nicht gesiegt hatten. Aber er gehorchte und blieb, wo er war. Lenin ernannte den 32-jährigen Nikolai Krylenko zum Oberbefehlshaber und schickte ihn in Begleitung einiger hundert Matrosen und Soldaten nach Mogiljow, um das Hauptquartier unter die Kontrolle der neuen Regierung zu bringen. Unmittelbar nach seiner Ankunft beorderte Krylenko Duchonin in seinen Dienstwaggon. Als der General den Waggon betrat, wurde er in Anwesenheit Krylenkos von Matrosen auf "viehische Weise» getötet, wie sich Bubnow

52 Zitiert in Sebestyen, Victor: Lenin. Ein Leben, Berlin 2017, hier S. 335.

53 Zitiert in: Latyšev, Anatolij: Rassekrečennyj Lenin, Moskau 1996, hier S. 85. Zur Strategie der Revolutionäre, den Angriff als Verteidigung umzudeuten vgl. Reemtsma, Jan-Philipp: Machtergreifung als konkrete Utopie oder Was heißt schon "Symbolpolitik«?, in: Berliner Colloquien zur Zeitgeschichte. Beilage zum Mittelweg 36 (2016) 1, S. $79-98$. 
erinnerte. Duchonins Leiche wurde entkleidet, auf die Straße geworfen und zur Belustigung der Matrosen tagelang malträtiert. ${ }^{54}$

Auf die Skrupellosigkeit der neuen Machthaber waren Sozialdemokraten und Liberale nicht vorbereitet. Sie konnten sich überhaupt nicht vorstellen, dass Lenin und seine Anhänger Gruppen, Schichten, Klassen zu Aussätzigen und Vogelfreien erklären und vernichten würden. Der Provisorischen Regierung habe es an »jakobinischer Unerschrockenheit» und Verantwortungslosigkeit gefehlt, sie habe gegen ihre Widersacher keine Gewalt anwenden wollen, schrieb Nabokow, der selbst ein feinsinniger und kultivierter Mann von liberaler Gesinnung war. Die Bolschewiki aber hätten keine Skrupel gehabt. "Die gegenwärtigen Herren der Lage, die Herren Bolschewisten ... haben sich freilich derartige Fragen niemals gestellt, und allein schon die Tatsache, daß sie gestellt werden konnten, hätte bei den Lenins und Trotzkis offenen Hohn hervorgerufen. Ihnen ist das Schicksal von einzelnen völlig gleichgültig. «55 Es ist wahrlich keine Überraschung, dass Carl Schmitt von einem Mann wie Lenin fasziniert war, von einem, der sich nur am eigenen Willen orientierte und tat, was er glaubte, tun zu müssen. Die Gewaltanwendung der Massen sei ein "Ausdruck unmittelbaren Lebens«, Lenins Revolution habe dem »russischen Haß gegen die Kompliziertheit, Künstlichkeit und den Intellektualismus westeuropäischer Zivilisation neues Leben gegeben und von ihm selber neues Leben empfangen«, schrieb er 1923, unmittelbar nach dem Ende des Bürgerkrieges. ${ }^{56}$

Zu Beginn hatte Lenin einfach keine andere Wahl, als aus der Not eine Tugend zu machen. Wenn man schon keine Kontrolle ausübte, konnte man potentielle Gegner wenigstens daran hindern, sich gegen die neuen Herren zu verbünden. Lenin wusste sehr genau, was er bewirken konnte, als er das Werk der Zerstörung beschwor und die Leidenschaften der Massen entfachte. Je größer das Chaos, desto geringer würden die Chancen seiner Gegner sein, sich gegen ihn und seine Anhänger zu verbünden. Lenin habe die "spontanen Ausbrüche» und "terroristischen Neigungen der Masse» bedenkenlos zu seiner Waffe gemacht, erinnerte sich der linke Sozialrevolutionär Isaak Steinberg an die ersten Monate der bolschewistischen Herrschaft. ${ }^{57}$ Und so wurden Furcht und Schrecken, Terror gegen jedermann und zu jeder Zeit zu Ressourcen, ohne die sich die Macht nicht am Leben hätte erhalten können. »Die Herren Volkskommissare», klagte Maxim Gor-

54 Bubnov, V carskoj stavke, S. 363 f.; Kotkin, Stalin, Bd. 1, S. 248.

55 Nabokow, Der kurze Sommer der Revolution, S. 50.

56 Schmitt, Carl: Die geistesgeschichtliche Lage des heutigen Parlamentarismus, 10. Aufl., Berlin 2010, hier S. 84, 87. Vgl. dazu auch Kesting, Hanno: Lenin, in: Alfred Weber: Einführung in die Soziologie, München 1955, S. $120-143$.

57 Štejnberg, Nrastvennyj lik revoljucii, S. 42. 
ki Ende Dezember 1917, »haben im Namen des Proletariats die alten Gerichte abgeschafft und dadurch die ıLynchjustizı, das tierische Recht der ıStraßeı zum Gesetz erhoben. «58 Adlige mussten unter Aufsicht von Soldaten Latrinen säubern und Straßen kehren, jeder Bewaffnete konnte, wenn es ihm gefiel, einen Menschen töten. In Kronstadt, der Marinebasis vor den Toren der Hauptstadt, terrorisierten Matrosen nicht nur ihre ehemaligen Offiziere, sondern auch die Bewohner, die auf der Insel lebten. Der Lynchmord wurde zum Tagesgeschäft. Auf den Straßen wurden Diebe und Landstreicher getötet, in Flüssen ertränkt oder einfach erschossen.59 Noch zwei Monate nach der Machtergreifung ratterten die Maschinengewehre auf den Straßen Petrograds. An jedem Tag lägen Tote auf der Straße, notierte Sinaida Hippius am 5. Dezember 1917, «überall Raub und Schießereien«, an die man sich schon gewöhnt habe. ${ }^{60}$

Im Dezember 1917 erklärte die Regierung, dass die liberale Partei der Konstitutionellen Demokraten außerhalb des Gesetzes stehe. Ihre Mitglieder wurden für vogelfrei erklärt. Dieser barbarische Akt, der an die niedrigsten Instinkte appellierte und »in empörendem Widerspruch zum Geist des Sozialismus stand», so sah es Steinberg im Rückblick, habe in den Volksmassen die Vorstellung entwickelt, dass für all ihre Leiden Menschen aus den besitzenden Klassen verantwortlich gemacht und getötet werden dürften, ganz gleich, ob ihnen eine Schandtat vorgeworfen werden konnte.61 Wenig später ermordeten verrohte Matrosen im Gefängnishospital von Petrograd die liberalen Politiker Andrei Schingarjow und Fjodor Kokoschkin, weil sie glaubten, dass der Mord an Gegnern der neuen Ordnung nicht gesühnt werden würde. ${ }^{62}$

Am 22. Februar 1918, als deutsche Armeen die Hauptstadt bedrohten, gab der Rat der Volkskommissare auch öffentlich bekannt, dass die Ermordung von Klassenfeinden erlaubt sei. »Feindliche Agenten, Spekulanten, Rowdies, Hooligans, konterrevolutionären Agitatoren, deutsche Spione sind am Ort des Verbrechens zu erschießen«, hieß es in der Instruktion. Alle arbeitsfähigen »Mitglieder der bourgeoisen Klasse«, Männer wie Frauen, sollten unter Aufsicht von Rotgardisten Schützengräben ausheben. „Wer Widerstand leistet, ist zu erschießen."Sie, die Linken Sozialrevolutionäre, hätten gegen solchen Terror protestiert, seien im Rat der Volkskommissare aber überstimmt worden. Und so hätten auch sie die Verheißung der Revolution, eine bessere Welt zu schaffen, aus billigem Interesse an

58 Gorkij, Maxim: Unzeitgemäße Gedanken über Kultur und Revolution, Frankfurt am Main 1974, hier S. 123.

59 Hasegawa, Crime and Punishment, S. $192-227$.

60 Hippius, Petersburger Tagebücher, S. 256.

61 Stejnberg, Nravstvennyj lik revoljucii, S. 45.

62 Gorkij, Unzeitgemäße Betrachtungen, S. 142; Štejnberg, Nrastvennyj lik revoljucii, S. 43, 49. 
der Macht schmählich verraten, gestand Steinberg später ein ${ }^{63}$. Die Botschaft konnte deutlicher nicht sein. Jeder, der ein Gewehr in der Hand halten durfte und sich zum Anhänger der neuen Ordnung erklärte, konnte sich nunmehr selbst ermächtigen, anderen Gewalt anzutun. Die Lynchjustiz war die eigentliche Signatur bolschewistischer Herrschaft. "Das Feuer ist angezündet, aber es brennt schlecht», schrieb Gorki am 3. März 1918, "es stinkt nach Rußland, dem schmutzigen, betrunkenen, grausamen Rußland. Sie stoßen und zerren dieses unglückliche Rußland nach Golgatha, um es zu kreuzigen, damit die Welt gerettet werde. ${ }^{64}$

Erst als den Machthabern das blutige Geschehen aus den Händen zu gleiten drohte, versuchten sie, die Gewalt zentraler Lenkung zu unterwerfen und in systematischen Terror zu verwandeln. Am 12. April 1918 erteilte der Vorsitzende der Tscheka, Felix Dserschinski, den Befehl, alle Anarchisten in Moskau zu entwaffnen und zu verhaften. Am gleichen Tag stellte er ihnen ein Ultimatum zu: „Die Allrussische Außerordentliche Kommission zur Bekämpfung der Konterrevolution fordert Sie auf, im Verlaufe der nächsten fünf Minuten alle in Ihren Händen befindlichen Waffen abzugeben, anderenfalls werden wir mit Ihnen wie mit Feinden der Sowjetmacht verfahren.«65 Am 16. April gab Dserschinski den »Iswestija», dem Presseorgan der Regierung, ein Interview. Er erklärte, dass sich die Anarchisten in Moskau mit Kriminellen verbündet und mit Drogen gehandelt hätten. Die Tscheka sei nicht nur zu dem Zweck gegründet worden, die Konterrevolution, sondern auch die "Kriminalität in all ihren Erscheinungen« zu bekämpfen. »Wir werden jetzt mit aller Energie die von uns begonnene Aktion fortsetzen, um die Stadt von kriminellen Elementen zu säubern. «66

Die »Säuberung« Moskaus war eine äußerst rücksichtslose und blutige Aktion. Beim Sturm auf die Häuser, in denen sich die Anarchisten verschanzt hatten, wurden mehr als vierzig Menschen getötet, 500 verhaftet. ${ }^{67}$ Lockart durfte in Begleitung von Jakob Peters, dem Stellvertreter Dserschinskis, die Orte des Gemetzels besichtigen: "Auf der Powarskaja, wo früher die reichen Kaufleute lebten, besichtigten wir ein Haus nach dem anderen. Die Verwahrlosung war haarsträubend. Zerbrochene Flaschen auf dem Fußboden, Schußspuren in den Decken, Weinflecken und menschlicher Kot auf den Aubussonteppichen. Wertvolle Gemälde waren zu Fetzen zerrissen. Noch lagen die Toten, wo und wie sie

\footnotetext{
63 Štejnberg, Nravstvennyj lik revoljucii, S. $52 \mathrm{f}$.

64 Gorkij, Unzeitgemäße Gedanken, S. 150.

65 Plechanova, A. A./ Plechanov, A. M. (Hrsg.): F. Ė. Dzeržinskij - predsedatel' VČK-OGPU 1917-1926

(Rossija XX vek), Moskau 2007, S. $36 \mathrm{f}$.

66 Plechanova, Dzeržinskij, S. $38 \mathrm{f}$.

67 Leggett, George: The Chela. Lenin's Political Police, Oxford 1981, hier S. 35.
} 
gefallen waren, darunter Offiziere in Gardeuniform, Studenten unter zwanzig, aber auch Männer, die offenbar den Verbrecherklassen angehörten, denen erst die Revolution die Gefängnisse geöffnet hatte. In dem eleganten Salon des Dom Gratschewa waren die Anarchisten mitten in einer Orgie überrascht worden. Die lange, gedeckte Tafel war umgeworfen, zerbrochenes Geschirr und Glas lag in Tümpeln von Blut und vergossenem Wein. Mit dem Gesicht zu Boden lag eine junge Frau. Peters drehte sie um. Ihr Haar war zerzaust, von einem Genickschuss war das Blut zu einem unheimlichen Klumpen geronnen. Sie war höchstens zwanzig Jahre alt. Peters zuckte mit den Achseln: `Prostitutka. Vielleicht ist's besser so. Dieses Bild vergesse ich nie. Die Bolschewiken fingen an aufzuräumen. «68 Wenige Wochen später, Ende Juni 1918, verschickte Dserschinski ein Zirkular an alle Dienststellen der Geheimpolizei in den Provinzen und erteilte ihnen die Anweisung, Waffen aller Art zu konfiszieren und jeden »streng zu bestrafen«, der sich den Anordnungen der Geheimpolizei widersetze. ${ }^{69}$

Am 6. Juli 1918 töteten Agenten der Tscheka, die der Partei der Linken Sozialrevolutionäre angehörten, den deutschen Botschafter, Wilhelm Graf von Mirbach. Kurz darauf besetzten Soldaten, die sich ihnen angeschlossen hatten, die Zentrale der Tscheka, nahmen Dserschinski und seinen Stellvertreter als Geiseln und brachten das Post- und Telegraphenamt unter ihre Kontrolle. Von dort versandten sie ihr Glaubensbekenntnis in alle Regionen Russlands, aber sie verzichteten darauf, den Kreml zu erobern und Lenin und seine Regierung festzusetzen. Nicht Usurpatoren wollten sie sein, sondern Mahner. Die Bolschewiki sollten sich auf ihre revolutionären Traditionen besinnen, die Diktatur beenden und den Krieg gegen die deutschen Imperialisten wieder aufnehmen. An einem Putsch hatten sie kein Interesse. Für solche Dilettanten, „demoralisierte Schwarzmeermatrosen und ehemalige entwaffnete Anarchisten«, empfanden Lenin und Dserschinski nichts als Verachtung. Er schickte ihnen eine Einheit loyaler Soldaten entgegen, ließ sie entwaffnen und zwang sie zur Kapitulation. Die Tscheka konfiszierte die Druckerei der Sozialrevolutionäre, 200 Aufständische wurden ohne Prozess erschossen. ${ }^{70}$

Am gleichen Tag hatten sich auch in Jaroslawl Sozialrevolutionäre gegen die Bolschewiki erhoben. Nach mehrstündigem Kampf mussten sie sich geschlagen geben, ihr Anführer, der berühmte Terrorist und Abenteurer, Boris Sawinkow, entkam allerdings. Nur drei Wochen später, am 30. August tötete der Sozialrevo-

68 Lockart, Vom Wirbel erfaßt, S. 138 f., $238 \mathrm{f}$.

69 Plechanova, Dzeržinskij, S. $53 \mathrm{f}$.

70 Plechanova, Dzeržinskij, S. 56-58. Die Dokumentation der Ereignisse aus der Perspektive der Tscheka findet sich im Dokumentenband: Krasnaja Kniga VČK, Bd. 1, Moskau 1989, S. 182 - 310; Leggett, The Cheka, S. 70-83; Kotkin, Stalin, Bd. 1, S. 278. 
lutionär Leonid Kannegiesser den Chef der Tscheka von Petrograd, Moisei Urizki, und am gleichen Tag gab die Terroristin Fanny Kaplan mehrere Schüsse auf Lenin ab, als er eine Fabrik verließ, in der er eine Rede gehalten hatte. Lenin wurde lebensgefährlich verletzt, überstand aber das Attentat. ${ }^{71}$ Wenngleich die Bolschewiki alle Erhebungen mit leichter Hand niederschlugen, begriffen sie doch sofort, dass ihre Macht auf tönernen Füßen stand. Nicht einmal in ihrer eigenen Umgebung konnten sie vor Verrat und Verschwörungen sicher sein. Warum sollte den Terroristen nicht gelingen, was ihnen am 1. März 1881 gelungen war, als sie Alexander II. am helllichten Tag in St. Petersburg getötet hatten? Der bedrohte Leviathan. Dieses Bild hatten Lenin und die Seinen stets vor Augen, weil niemand besser wusste als sie, was kleine, aber entschlossene Gruppen von Menschen bewirken konnten. ${ }^{72}$ Was hat der Machthaber von seiner Macht, wenn er jederzeit damit rechnen muss, umgebracht zu werden? Überall sieht er Feinde und Verschwörer, er verschanzt sich hinter dicken Mauern und umgibt sich nur noch mit Seinesgleichen, mit Vertrauten, auf deren Loyalität er sich jederzeit verlassen kann.

Die Zentralisierung und Systematisierung der Gewalt kam aus der Furcht der bolschewistischen Führer, Opfer der Verhältnisse zu werden, die sie selbst geschaffen hatten. Trotzki, der die Gewalt anbetete wie kein anderer Bolschewik, gestand offen ein, dass der Terror das einzige Instrument war, dessen sich die Diktatur im Kampf um ihr Überleben bedienen konnte: „Denn gegen eine reaktionäre Klasse zur Anwendung gebracht, die nicht den Schauplatz verlassen will, kann der Terror sehr wirksam sein. Die Abschreckung ist ein machtvolles Mittel der Politik, der internationalen wie der inneren. Der Krieg ist ebenso wie auch die Revolution auf Abschreckung gegründet. Der allgemeinen Regel nach vernichtet der siegreiche Krieg nur einen unbedeutenden Teil der besiegten Armee, die Übrigen schreckt er ab und bricht so ihren Willen. Ebenso wirkt die Revolution: sie tötet Einzelne und schreckt Tausende ab. In diesem Sinne unterscheidet sich der rote Terror prinzipiell nicht vom bewaffneten Aufstand, dessen direkte Fortsetzung er ist. Den staatlichen Terror der revolutionären Klasse kann nur der ımoralisch verurteilen, der überhaupt jede Gewalttätigkeit - folglich auch jeden Krieg und jeden Aufstand - prinzipiell (in Worten!) ablehnt. Dazu muß man einfach ein heuchlerischer Quäker sein. «73 Trotzki nahm den Gedanken der stalinistischen Despotie, die Toten zu vermehren, um die Lebenden zu unterwerfen, schon

71 Service, Robert: Lenin. Eine Biographie, München 2000, hier S. 475 - 479.

72 Thunemann, Fabian: Verschwörungsdenken und Machtkalkül. Herrschaft in Russland, 1866 - 1953

(Ordnungssysteme. Studien zur Ideengeschichte der Neuzeit, Bd. 53), München 2019, hier S. 95 - 119.

73 Trotzki, Terrorismus und Kommunismus, S. 43. 
vorweg. Man tötet den einen, am nächsten Tag einen anderen, und man zeigt den Untertanen, dass man kann, was man will. Allmacht hat nur, wer jederzeit und überall töten kann, wen er töten will. ${ }^{74}$

Unmittelbar nach dem Attentat auf Lenin am 5. September 1918 gaben die Volkskommissare für Justiz und Innere Angelegenheiten, Dmitri Kurski und Grigori Petrowski, bekannt, dass die Anwendung von Terror zur Verteidigung der neuen Ordnung notwendig und geboten, jedermann verpflichtet sei, der Tscheka zur Hand zu gehen. Vor Bedrohungen könne die Sowjetmacht nur sicher sein, wenn Klassenfeinde in Konzentrationslagern isoliert und alle Personen erschossen würden, die mit "weißgardistischen Organisationen, Verschwörungen und Aufständen« in Verbindung stünden. Die Namen der Erschossenen sollten zur Abschreckung veröffentlicht werden. Wann hatte es jemals eine Regierung gegeben, die ausgerechnet ihren Justizminister damit beauftragte, öffentlich zu erklären, dass Recht und Gesetz außer Kraft gesetzt seien ?75

Die Tscheka machte sich umgehend ans Werk, ihre Einheiten durchkämmten Häuser und Wohnungen, sie nahmen Geiseln und brachten sie in Gefängnisse und Lager. Ihre Namen wurden in den "Iswestija" mit dem Hinweis veröffentlicht, dass sie alle erschossen werden würden, sollte auch nur ein einziger Funktionär des Regimes getötet werden. In den ersten Tagen nach dem Attentat auf Lenin tötete die Tscheka allein in Petrograd mehr als 800 »Klassenfeinde», unter ihnen auch den ehemaligen Justizminister des Zaren, Iwan Schtscheglowitow, die früheren Innenminister Alexei Chwostow, Nikolai Maklakow und Alexander Protopopow, den Polizeichef des Zaren, Stepan Belezki und den Bischof Iwan Wostorgow, die aus dem Gefängnis geholt und mitten am Tag im Petrowski-Park, einer Grünfläche an der nördlichen Stadtgrenze, erschossen und ihre Leichen danach gefleddert wurden. ${ }^{76}$ Grigori Sinowjew, der Parteichef von Petrograd, ließ am 7. September in den "Iswestija» mitteilen, dass in seiner Stadt bereits 500 Geiseln, vor allem Funktionsträger des alten Regimes, öffentlich ermordet worden seien. Es sollten nicht die letzten Geiseln sein, die erschossen wurden. Bis Ende Oktober fielen mehr als 6.000 Menschen dem Terror der Tscheka zum Opfer. ${ }^{77}$

Der Terror erzeugte eine Atmosphäre allgegenwärtiger Angst. Allein beim Anblick eines betrunkenen Soldaten oder eines kokainsüchtigen Tschekisten, beim ersten Schuss, der auf der Straße zu hören war, schlossen sich allenthalben Fens-

74 Canetti, Elias: Masse und Macht, München 1960, hier S. 503 - 515. Zur Funktion der Gewalt in der stalinistischen Diktatur vgl. Baberowski, Jörg: Verbrannte Erde. Stalins Herrschaft der Gewalt, München 2012.

75 Postanovlenie SNK o krasnom terrore, 5 sentjabrja 1918 g., in: Plechanova, Dzeržinskij, S. 70.

76 Latyšev, Rassekrečennyj Lenin, S. 84; Leggett, The Cheka, S. $102-120$.

77 Izvestija, 7. September 1918; Kotkin, Stalin, Bd. 1, S. 287. 
ter und die Türen. In allen Regionen des Imperiums, die sich unter der Kontrolle der Bolschewiki befanden, begann nun die große Menschenjagd. Tag für Tag wurden Häuser durchsucht, tausende Menschen verschleppt, tausende Geiseln erschossen und ihre Namen in der Presse veröffentlicht. Auch Bauern bekamen die Gewalt zu spüren, als sie sich den Beschaffungsbrigaden widersetzten, die in ihren Dörfern Getreide für die Versorgung der Städte konfiszieren und Soldaten für die Rote Armee rekrutieren wollten. Wie überall, so verschwamm der revolutionäre Furor der Bolschewiki auch hier mit der kriminellen Lust an der Gewalt, Frauen, die vergewaltigt, Bauern, die aufgehängt oder durch Maschinengewehrsalven hingerichtet wurden. ${ }^{78}$

Der Krieg auf dem Dorf wurde mit einer Brutalität ausgetragen, die es seit den Raubzügen Pugatschows nicht mehr gegeben hatte. Am 11. August 1918 telegraphierte Lenin nach Pensa: "Genossen! Der Aufstand in fünf Kulaken-Bezirken muß gnadenlos niedergeschlagen werden. Dies erfordert das Interesse der gesamten Revolution, denn jetzt muß der letzte, entscheidende Kampf gegen die Kulaken geführt werden. Man sollte ihn auf folgende Weise erproben: 1 . Nicht weniger als 100 berüchtigte Kulaken, Reiche und Blutsauger aufhängen (es ist unverzichtbar, sie aufzuhängen, damit das Volk es sieht), 2. ihre Namen veröffentlichen, 3. ihnen alles Getreide abnehmen, 4. Geiseln festlegen, in Übereinstimmung mit dem gestrigen Telegramm. So muß man es machen, damit das Volk im Umkreis von 100 Werst alles sieht, erfährt, zittert und schreit: man stranguliert die blutsaugenden Kulaken. Telegraphieren Sie den Erhalt des Befehls und seine Ausführung. Ihr Lenin. P.S. Suchen Sie harte Leute dafür aus!» Zwei Tage zuvor hatte er den Genossen in Nischni-Nowgorod empfohlen, das Gouvernement mit "Massenterror" zu überziehen und "hunderte Prostituierte» zu erschießen. ${ }^{79}$

Die Bolschewiki waren sich ihrer Sache nicht sicher, aber sie machten die Erfahrung, dass Drohungen ihre Wirkung verloren, wenn ihnen keine Taten folgten und wenn sie die Gewalt in das Belieben von Jedermann stellten. „Die Bolschewiken haben sich auf physische Gewalt festgelegt. Und das dauerhaft", schrieb Sinaida Hippius am 1. September 1918 in ihr Tagebuch. Auch die Autokratie habe sich auf Gewalt gestützt, um die Ordnung zu schützen, allerdings auf Gewalt, die durch Recht und Tradition gleichermaßen legitimiert gewesen sei. "Aber da sie über keine entsprechenden Gewohnheiten und Traditionen verfügen, müssen die Bolschewiken, wenn sie die Stabilität der Selbstherrschaft erreichen wollen, die

78 Buldakov, Vladimir: Krasnaja smuta. Priroda i posledstvija revoljucionnogo nasilija (Istorija stalinizma), Moskau 2010, S. $475 \mathrm{f}$.

79 Latyšev, Rassekrečennyj Lenin, S. 27, 57. 
Gewalt in einem gewaltigen Ausmaß steigern. Das tun sie auch. Das entspricht nationalen `Besonderheiten` des russischen Volkes, die einem Europäer unverständlich sind. Je grausamer die Macht, desto mehr kann sie sich erlauben, und desto mehr erlaubt man ihr.«80 Und man könnte hinzufügen: je weniger Macht jemand hat, desto größer ist sein Bedürfnis, immer wieder auf sie hinzuweisen.

Im Angesicht der Gewalt und in ihrer Ohnmacht und Hilflosigkeit konnten sich die Verängstigten und Verschreckten gegen die zu Allem entschlossenen Revolutionäre nicht wehren. Es gab nach Jahren des Krieges und der Entbehrungen keine Instanz mehr, die Widerstand hätte organisieren können. Bunin erinnerte sich an die dunklen und bedrückenden Stunden, die er im Frühjahr 1919 in Odessa verlebte: „Gestern am frühen Abend gingen wir spazieren. Unsägliche Schwere auf meiner Seele. Die Menge, die jetzt die Straße bevölkert, ist physisch unerträglich, ich bin am Ende meiner Kräfte, so satt habe ich diese viehische Menge. Wenn man ausruhen könnte, sich irgendwo verstecken, verreisen, zum Beispiel nach Australien! Doch schon längst sind alle Wege, alle Straßen versperrt. Heutzutage ist es bereits ein verrückter Wunschtraum, nach Bolschoi Fontan zu fahren: ohne Genehmigung ist es verboten, und sie können Dich töten wie einen Hund. ${ }^{81}$

Die Revolution verschlang ihre Kinder, die Bolschewiki triumphierten, und sie schickten Aufklärer und Liberale auf den Müllhaufen der Geschichte. Kein Liberaler mochte 1920 noch glauben, was im Jahr 1917 für eine Gewissheit gehalten werden konnte: dass der Sieg des bürgerlichen Freiheitsprojekts unvermeidlich sei. Pawel Miljukow, das prominenteste Gesicht des russischen Liberalismus, gab sich keinen Illusionen hin. Nicht am Wettstreit der Ideen sei die russische Demokratie zerbrochen, sondern an ihrer Isolation vom Volk, an ihrer Unentschlossenheit und Zaghaftigkeit. Es habe nur eines Anstoßes bedurft, um das Riesenreich und seine Staatsmaschine zu zertrümmern. Im Chaos, das der Untergang ausgelöst habe, hätten sich dann aber nur entschlossene und skrupellose Gewalttäter durchsetzen können. Der Bolschewismus sei ein Phänomen russischer Rückständigkeit und schwacher Staatlichkeit, keine Repräsentation des europäischen Marxismus. „Was den fremden Beobachter an den gegenwärtigen Ereignissen verblüfft, ... das war dem Soziologen und dem Erforscher der russischen historischen Entwicklung schon lange bekannt. Für ihn sind Lenin und Trotzki Führer einer Bewegung, die Pugatschow, Rasin und Bolotnikow, dem 18. und

80 Hippius, Petersburger Tagebücher, S. 377. Vgl. auch Beyrau, Dietrich: The Long Shadow of the Revolution: Violence in War and Peace in the Soviet Union, in: Legacies of Violence. Eastern Europe's First World War (Europas Osten im 20. Jahrhundert, Bd. 3), hrsg.von Jochen Böhler/ Wlodzimierz Borodzeij/ Joachim von Puttkamer, München 2014, S. 285 - 316.

81 Bunin, Verfluchte Tage, S. 63. 
17. Jahrhundert unserer Geschichte viel näherstehen als den letzten Worten des europäischen Anarcho-Syndikalismus. ${ }^{82}$

Der russische Bürgerkrieg, der im Sommer 1918 begann und erst 1921 ein Ende fand, war ein verheerendes Geschehen. Zehn Millionen Menschen wurden im Kampf getötet, ermordet, starben an Hunger, Unterernährung oder an Epidemien. Ganze Landstriche waren entvölkert, Metropolen verwandelten sich in Orte der Ödnis, nachdem die Geißel des Krieges sie verheert hatte. ${ }^{83}$ Russland war 1921 nicht nur ein Bauernland ohne Proletariat, es war auch ein Land ohne geistige Elite. In einem symbolischen Akt beendete Lenin 1922 die Geschichte der Petersburger Kultur, als er Stalin die Anweisung erteilte, prominente Professoren, Philosophen, Schriftsteller und Künstler aus Russland auszuweisen, unter ihnen Semjon Frank, Sergei Trubezkoi, Alexander Kisewetter, Nikolai Berdjajew, Michail Ossorgin, Alexander Isgojew und Sergei Bulgakow. „Säubern wir Rußland für lange Zeit «. ${ }^{84}$ Als das Philosophenschiff die Segel setzte, verschwanden das alte Europa und seine geistige Kultur aus dem russischen Leben.

Mord und Vertreibung leerten Russlands geistige Gefäße, aber sie öffneten auch die Tore für ehrgeizige Aufsteiger, die in der Stunde der Not die Plätze der Ermordeten und Vertriebenen einnahmen. Der Krieg war nicht nur ein Geschehen der Entgrenzung, sondern auch der Gefolgschaftsbindung und Disziplin. Erst im Kugelhagel des Bürgerkriegs wurde der bolschewistische Funktionär gestählt. ${ }^{85}$ „Der Krieg gab uns die Kraft», so Lenin im Jahr 1920, »die Disziplin bis zum Maximum zu treiben und zehntausende, hunderttausende Leute, Genossen, zu zentralisieren, die gestorben sind, um die Sowjetrepublik zu retten. Ohne das wäre alles zum Teufel gegangen. ( $^{86} \mathrm{Nicht}$ feinsinnige Marx-Interpreten, sondern Männer der Tat und der Gewalt gaben dem neuen Staat ein Gesicht. Nicht Marxismus und Theorie, sondern Krieg und Exzess waren die Väter der bolschewistischen Dikta-

\footnotetext{
82 Miljukov, Istorija vtoroj russkoj revoljucii, S. $17 \mathrm{f}$.

83 Zum Bürgerkrieg vgl. exemplarisch: Engelstein, Laura: Russia in Flames. War, Revolution, Civil War 1914-1921, Oxford 2018; Smele, Jonathan: The "Russian« Civil Wars. 1916-1926. Ten Years that Shook the World, London 2015; Sunderland, Willard: The Baron's Cloak. A History of the Russian Empire in War and Revolution, Ithaca/ N.Y. 2014.

84 Artizov, Andrei u.a. (Hrsg.): „Očistim Rossiju nadolgo ...» repressii protiv inakomysljaščich. Konec 1921 - načalo 1923 g. (Rossija XX vek), Moskau 2008, hier S. 162.

85 Eine einfühlsame Schilderung der Zurichtung findet sich bei: Šklovskij, Viktor: Sentimentale Reise (Bibliothek Suhrkamp, Bd. 390), Frankfurt am Main 1974. Zum Erbe des Bürgerkrieges vgl. Lewin, Moshe: The Civil War. Dynamics and Legacy, in: Party, State, and Society in the Russian Civil War. Explorations in Social History (Indiana-Michigan series in Russian and East European studies), hrsg. von Diane Koenker/ William Rosenberg, Bloomington/ Ind. 1989, S. 399 - 423; Pethybridge, Roger: The Social Prelude to Stalinism, London 1974.

86 Zitiert in: Latyšev, Rassekrečennyj Lenin, S. 77.
} 
tur und ihrer autoritären Kultur. In den Jahren des Bürgerkrieges wurde eingeübt, was Stalin später zum Prinzip seiner Herrschaft erheben würde. ${ }^{87}$

Das Gefühl der allgegenwärtigen Unsicherheit und Bedrohung formte Lebenshaltungen und Erwartungen nicht nur der Kommunisten, sondern auch der Untertanen, und es gab der souveränen Diktatur eine Rechtfertigung, die für jedermann verständlich war: Angst vor der Wiederkehr des entgrenzten Krieges. Dieses Motiv war allgegenwärtig. Michail Bulgakows Bürgerkriegsepos »Die weiße Garde», das in den Jahren 1923 und 1924 entstand, erzählt vom Leben und Sterben in der Katastrophe. Das alte Russland und seine Kultur verschwanden, und wer überleben wollte, hatte keine andere Wahl, als sich auf die Bedingungen einzustellen, die das Leben ihnen stellten. So erging es auch den Geschwistern Turbin, die Bulgakow durch die Wirren des Bürgerkrieges schickte und die erleben mussten, wie Rote und Weiße, Bauernhaufen, Nationalisten und Antisemiten Kiew in eine Frontstadt verwandelten, in der sich niemand mehr vor dem Tod in Sicherheit bringen konnte, die Angehörigen der alten Elite schon gar nicht. Am Ende aber arrangieren sich auch die Turbins mit den Siegern, den Bolschewiki. Denn sie brachten nicht nur Verderben, sondern auch Frieden. Was hätte es in dieser Zeit Wichtigeres geben können als im Frieden zu leben? Es war sicher kein Zufall, dass Stalin gefiel, was Bulgakow, der gewiss kein Freund der bolschewistischen Diktatur war, über das Leben in der Katastrophe zu Papier gebracht hatte. ${ }^{88}$

Nach Jahren des Bürgerkrieges und der Gewalt war das Band zerrissen, das Vorher und Nachher miteinander verbunden hatte. Nur noch die Erfahrung exzessiver Gewalt und Unsicherheit verband alle Menschen miteinander, Opfer wie Täter, Bauern wie Kommunisten und Adlige. Die Kultur des Misstrauens, die Furcht vor Anarchie, Chaos und Gewalt, der Kult des Machtstaates, der Ordnung schafft, richtete nicht nur die Bolschewiki, sondern auch ihre Gegner und Opfer zu, auf Dauer und mit Folgen für das Zusammenleben von Menschen nicht nur in der Sowjetunion, sondern auch im alten Europa. Sie war der Grund, auf dem die autoritären und totalitären Staaten des 20. Jahrhunderts errichtet wurden. ${ }^{89}$

Warum setzten sich in diesem revolutionären Geschehen ausgerechnet die Bolschewiki gegen alle Widerstände durch? Weil die Wenigen organisiert und entschlossen und die Vielen es nicht sind, weil die einen keine Skrupel haben, von

87 Buldakov, Krasnaja Smuta; Baberowski, Jörg: Verwüstetes Land. Macht und Gewalt in der frühen Sowjetunion, in: Gewalträume. Soziale Ordnungen im Ausnahmezustand (Eigene und fremde Welten. Repräsentationen sozialer Ordnungen im Wandel, Bd. 20), hrsg. von dems./ Gabriele Metzler, Frankfurt am Main 2012, S. 169 -188; Kotkin, Stalin, Bd. 1, S. 295; Schnell, Felix: Räume des Schreckens. Gewalt und Gruppenmilitanz in der Ukraine 1905 bis 1933 (Studien zur Gewaltgeschichte des 20. Jahrhunderts), Hamburg 2012.

88 Bulgakow, Michail: Die weiße Garde, München 1990.

89 Traverso, Im Bann der Gewalt, S. 75-118, 191-229. 
ihren Waffen Gebrauch zu machen und die anderen kein Wagnis eingehen wollen. Die Mächtigen erzwingen Gehorsam, dafür geben sie ihren Anhängern Ordnungssicherheit. Auf dieser Verabredung beruhen alle Machtbeziehungen. ${ }^{90}$ Bevor sie sich aber in Institutionen ablagern und verfestigen, müssen sie sich durchsetzen. Darum geht es in allen Revolutionen und Bürgerkriegen, in denen Staaten zerstört und neu errichtet werden. Die Legitimation der Herrschaft erwächst nicht allein aus dem Glauben an ihre Rechtmäßigkeit, sondern auch aus der Praxis der Machtsicherung, dem alltäglichen Beweis, dass Macht gegen Widerstand durchgesetzt werden kann. Die Anerkennung einer Ordnung beruht am Ende gar nicht auf politischen Überzeugungen, sie kann sich vielmehr an ihnen "vorbeientwickeln", wie Heinrich Popitz sagt.91 "Die Bolschewiki triumphierten letztlich nicht", schreibt Serge Schmemann über die Revolution im Dorf, "weil sie die größere Unterstützung aus dem Volk oder die größere Wahrheit auf ihrer Seite hatten, sondern weil sich in Zeiten der Wirren die am besten organisierte und rücksichtsloseste Kraft durchsetzt. Lenins ... Ideologie verlangte die Machtergreifung, und er setzte dieses Ziel mit einer straff disziplinierten und eifrigen Gefolgschaft und frei von Skrupeln und Patriotismus durch.«92

Manche Historiker sagen, das Ende des Bürgerkrieges sei auch das Ende der Revolution gewesen. Zwar war der Sieg der Bolschewiki das Ende der alten Ordnung und der Beginn einer neuen Welt, Gründungsakt des sowjetischen Imperiums. Aber er war auch der Anfang einer staatlich gelenkten Revolution, die sich über alle Bedenken und Skrupel hinwegsetzte. Stalins großem Sprung nach vorn, Industrialisierung, Kollektivierung und Kulturrevolution, fielen Millionen Menschen zum Opfer: Bauern, die erschossen, nach Sibirien deportiert wurden oder verhungerten, Priester, Adlige, Angehörige verbotener Parteien, die in den Lagern verschwanden oder den Tod fanden, ethnische Minoritäten, die Heimat und Freiheit verloren. Die Bolschewiki waren Zerstörer, und sie setzten das Werk der Zerstörung auch dann noch fort, als sie bereits an den Schalthebeln der Macht saßen. Sie führten Krieg gegen das alte Russland, gegen Religion und Tradition und gegen das Recht auf Leben. Einen solchen Feldzug, eine solche Verheerung hatte die Welt noch nicht gesehen. Die Bolschewiki waren Meister der Krise, die jede Festung schliffen und darin der Welt ein Beispiel dafür gaben, was es hieß, souverän zu sein. Im Angesicht des Terrors, der die weite Menschenebene verwüstete, verschwanden die letzten Reste zivilgesellschaftlichen Widerstands. In der Treib-

90 Popitz, Heinrich: Phänomene der Macht, 2. Aufl., Tübingen 1992; Baberowski, Jörg: Räume der Gewalt, Frankfurt am Main 2015, hier S. $195-213$.

91 Popitz, Phänomene der Macht, S. 226.

92 Schmemann, Serge: Ein Dorf in Rußland. Zwei Jahrhunderte russischer Geschichte, Berlin 1999, hier S. 240 . 
sandgesellschaft konnte die Despotie nach Belieben schalten und walten, ohne mit ernsthaftem Widerspruch rechnen zu müssen. ${ }^{93}$

Die souveräne Diktatur will die alte Ordnung beseitigen und eine neue aus dem Boden stampfen. Das aber gelingt ihr nur, indem sie das Recht suspendiert und den Bürgerkrieg heraufbeschwört. ${ }^{94}$ Ihn aber kann sie nicht fortsetzen, wenn sie sich nicht selbst aufs Spiel setzen will. Eine Ordnung, die darauf vertraute, sich nur durch Selbstzerstörung am Leben zu erhalten, verlöre am Ende den Boden unter den Füßen. Was könnte sie schon bewirken, wenn die Gewalt kein Ende findet, das Erreichte aber doch irgendwann einmal abgesichert werden muss? Herrschaft braucht Anerkennung, Verwurzelung, wenn sie sich in der Überlieferung einen Platz erobern will. Die souveräne Diktatur muss irgendwann aufhören, Diktatur zu sein und sich als Ordnung wieder in Tradition und Form verwurzeln, wenn sie den Tag überdauern will, an dem sie zur Welt gekommen ist. Der Mensch träumt vom Anfang, der alles vergessen und Neues beginnen lässt. Aber wo immer er auch anfängt, trifft er auf Vorgefundenes, mit dem er zurechtkommen muss. "Je schneller das Neueste zum Alten wird" schreibt der Philosoph Odo Marquardt, »desto schneller kann Altes wieder zum Neuesten werden «. ${ }^{95}$

Unter Stalins Nachfolgern verwandelte sich die Diktatur in eine autoritäre Ordnung, der Terror verschwand aus dem Leben von Millionen. Die späte Sowjetunion war ein Ort politischer Bewegungslosigkeit, einer Normalität, die von den meisten Menschen als Erlösung von finsterer Vergangenheit empfunden wurde. Was war denn Leonid Breschnjew anderes als die plebejische Variante Alexanders III., einer, der sich für einen Kommunisten hielt, aber doch nur eine konservative Repräsentation einer genügsamen Wirklichkeit war? Je heftiger die Erschütterungen, und je häufiger die Nachbeben, die das Leben aus den Angeln heben, desto größer ist das Bedürfnis, sich in einer stabilen Ordnung einzurichten. Wie immer man die Revolution und ihre Folgen auch beurteilen mag, eines ist doch gewiss: Der Blick in den Abgrund hatte sich nicht gelohnt. Es gab dort nichts zu sehen.

93 Lewin, Moshe: The Social Background of Stalinism, in: Ders.: The Making of the Soviet System. Essays in the Social History of Interwar Russia, New York 1985, S. 258-285; Ders.: Grappling with Stalinism, in: Ders.: The Making of the Soviet System. Essays in the Social History of Interwar Russia, New York 1985, S. 286 - 314; Baberowski, Verbrannte Erde.

94 Schmitt, Carl: Die Diktatur. Von den Anfängen des modernen Souveränitätsgedankens bis zum proletarischen Klassenkampf, 8. Aufl., Berlin 2015 (erstmals 1921), hier S. 134-137. Vgl. auch Baberowski, Jörg: Diktatur und Gewalt, in: Diktaturen. Perspektiven der zeithistorischen Forschung (Zeitgeschichte im Gespräch, Bd. 29), hrsg. von Johannes Hürter/ Hermann Wentker, Berlin 2019, S. 156 - 166.

95 Marquardt, Odo: Zukunft braucht Herkunft. Philosophische Betrachtungen über Modernität und Menschlichkeit, in: Ders.: Philosophie des Stattdessen (Universal-Bibliothek, Bd. 18049), Stuttgart 2000, S. $66-78$, hier S. 73 für das Zitat. 